Columbia Law School

Scholarship Archive

1985

\title{
Sharing Among the Human Capitalists: An Economic Inquiry into the Corporate Law Firm and How Partners Split Profits
}

Ronald J. Gilson

Columbia Law School, rgilson@law.columbia.edu

Robert H. Mnookin

Follow this and additional works at: https://scholarship.law.columbia.edu/faculty_scholarship

Part of the Business Organizations Law Commons, and the Law and Economics Commons

\section{Recommended Citation}

Ronald J. Gilson \& Robert H. Mnookin, Sharing Among the Human Capitalists: An Economic Inquiry into the Corporate Law Firm and How Partners Split Profits, 37 StAN. L. ReV. 313 (1985).

Available at: https://scholarship.law.columbia.edu/faculty_scholarship/897 


\section{Sharing Among the Human Capitalists: An Economic Inquiry into the Corporate Law Firm and How Partners Split Profits}

\section{Ronald J. Gilson and Robert H. Mnookin*}

Large corporate law firms seem to be in a state of extraordinary flux. Success and failure are both on the rise. Large firms appear to supply a substantial and growing proportion of the legal services consumed by American business enterprises ${ }^{1}$ and to hire a significant fraction of the graduating classes of elite

* Professors of Law, Stanford University. We are grateful to Ellen Borgersen, Thomas Jackson, Reinier Kraakman, Mitchell Polinsky, Roberta Romano, Myron Scholes, William Simon, and Prentiss Willson for their comments on an earlier draft of this article, to Robert Wise for research assistance, and to Steven Kelman and Peter Pashigian, who acted as commentators on this article at the 1984 Stanford Law School Symposium on The Law Firm as a Social Institution. Research for this article was supported by the Stanford Legal Research Fund, made possible by grants from a bequest from the Estate of Ira L. Lillick and by gifts from other friends of the Stanford Law School.

(C) 1985 by Ronald J. Gilson \& Robert H. Mnookin.

1. Law practice is big business in this country. A Commerce Department study indicates that American lawyers in private practice generated more than $\$ 38$ billion in gross income during 1983. This study also indicates that the legal industry's recent annual growth rate of over $12 \%$ is about triple that of the GNP in recent years. See Flaherty, The \$38 Billion Legal Market, Nat'l L.J., Jan. 30, 1984, at 2, col. 1, at 52, col. 2.

While we have found no data detailing the percentage of corporate legal work done by large firms, Internal Revenue Service income statistics for 1979 indicate that partnerships (not sole proprietors) provide the bulk of this work measured in dollar value. Roy, Income Statistics of Law Firms-From the IRS, 23 LAw OFF. Econ. \& MGMT. 447 (1983).

There is, however, very good data showing that attorney compensation rises with firm size. An indication of the distribution is provided in the following table, which is based on data drawn from Altman \& Weil, Inc., The 1982 SuRvey of Law Firm EcoNomics 71-72 (1982). Note that for firms of 40 or more attorneys included in the survey, the total average compensation per partner was $76 \%$ greater than that received by partners in firms made up of between two and six attorneys. 
American law schools. ${ }^{2}$ Moreover, the last twenty years have witnessed a remarkable expansion in both the number of large firms and the absolute size of the biggest. ${ }^{3}$ But accompanying this striking success, there are also signs of serious institutional instability. During the last few years, several previously successful large firms have disintegrated and collapsed. ${ }^{4}$ Every issue of the legal press now carries stories of individual partners leaving one

Id. at 63 .

Attorney Compensation As A Function of Firm Size (1982)

\begin{tabular}{|c|c|c|}
\hline Number Of & Number Of & \\
\hline Attorneys & Firms & Average Total \\
\hline in Firm & in Sample & Compensation \\
\hline $2-6$ & $180^{\circ}$ & $\$ 67,184$ \\
\hline $7-11$ & 94 & $\$ 82,174$ \\
\hline $12-19$ & 104 & $\$ 91,813$ \\
\hline $20-39$ & 90 & $\$ 104,124$ \\
\hline 40 or more & 62 & $\$ 118,173$ \\
\hline
\end{tabular}

Total Compensation as Percentage of Average for 2-6 Attorney Firms $100 \%$ $122 \%$ $137 \%$ $155 \%$ $176 \%$

2. Stanford Law School's placement office confirms, for example, that a large and growing percentage of Stanford graduates have accepted offers of permanent employment with law firms having more than $\mathbf{5 0}$ attorneys.

\section{Employment of Stanford Law School Graduates}

Class Size

Percentage of Class

Taking Employment with Private Firms of More than 50 Attorneys

Percentage of

Graduates Entering

Private Practice

Entering Firms with over 50 Attorneys

$\begin{array}{rrrrrl}1977 & 1978 & 1979 & 1980 & 1981 & 1982 \\ 143 & 162 & 179 & 168 & 171 & 162\end{array}$

$36 \% \quad 37 \% \quad 38 \% \quad 37 \% \quad 45 \% \quad 46 \%$

$\begin{array}{llllll}53 \% & 55 \% & 55 \% & 51 \% & 69 \% & 66 \%\end{array}$

3. In 1963, Shearman \& Sterling was the largest American law firm with 134 attorneys. See Cantor, Law Firms Are Getting Bigger . . . and More Complex, 64 A.B.A. J. 215 (1978) (statistics documenting the growth of the nation's largest law firms between 1963 and 1977). In 1983, 109 American firms had more than 134 attorneys. National Law Firm Survey: The 250 Largest Firms, Nat'l L.J., Sept. 19, 1983, at 12, col. 4. The average number of lawyers for the 100 largest firms was 217.53. Id. at 2, col. 2. See also Nelson, Practice and Privilege: Social Change and the Structure of Large Law Firms, 1981 AM. B. Found. RESEARCH J. 97, 109 (detailing growth of the largest Chicago firms) [hereinafter cited as Nelson, Practice and Privilege]; Hochberger, Law Joumal Survey Shows Growth of 20 Major Firms, N.Y.L.J., Mar. 16, 1981, at 1, col. 3 (detailing the growth of the largest New York firms).

4. See, e.g., Trigoboff, Too Much Growth Splits San Diego's Sullivan E Jones, L.A. Daily J., May 12, 1983, at 1, col. 2; Masters, Fulop E Hardee: The Demise of a Law Firm, L.A. Daily J., Feb. 4, 1983, at 6, col. 1; Brill, The Way They Were, Am. LAw., June 1982, at 1; Pollock, Kaplan, Livingston Falls Apart: Will the Last One Out Turn Off the Lights?, AM. Law., Nov. 1981 , at 36 . 
firm to join another, groups of partners splitting off to establish their own firms, and internal squabbles over the division of profits. ${ }^{5}$ Traditions like seniority-based divisions of partnership income $^{6}$ and the "up or out" policy, under which associates either

5. A sampling of recent articles reveals a common theme underlying law firm institutional instability: younger partners' dissatisfaction with firm management policies and partner compensation schemes.

The following account of recent troubles within a Los Angeles firm is by no means atypical:

Several weeks ago, when Robert Henigson, then an executive committee member at Lawler, Felix \& Hall, tried to coax longtime partner Leo Pircher into staying at the firm, he got more than he bargained for.

Besides demanding an enormous raise, Mr. Pircher-already the best-paid partner at Lawler Felix-presented what has since become known as the "hit list." It named half a dozen senior partners whom Mr. Pircher said would have to go if he were to remain at Lawler. And according to several insiders, he included the would-be peacemaker, Mr. Henigson, who had approached Mr. Pircher on his own.

A few weeks later, on Nov. 28, Mr. Pircher left his firm-home of nearly three decades . . . [and] spirited away two partners, 16 associates and about 20 support staffers-just about everyone in the department he once led . . . .

Other observers from within and without point to the defection of $\mathrm{Mr}$. Pircher's department as the latest symptom of a growing problem in large firms over the last ten years: senior partners who aren't producing enough to justify their high draws.

Galante, Pariner Leads Mass Exodus From L.A. Firm, Nat'l L.J., Dec. 19, 1983, at 3, col. 1. See also Brill, The Shakeout is Here: Dissension in the Ranks at Dewey, Ballantine and Donovan Leisure, Am. Law., July/Aug. 1983, at 1; Pollock, Partner Charges Firm Conspired to Oust Him, AM. LAw., Sept. 1980, at 14; Simon, Howrey E' Simon Hit By Fight Over Money, Nat'l L.J., Jan. 31, 1983, at 2, col. 4; Tell, Marshall Bratter Loses Seven Partners in a Rift, Nat'l L.J., Jan. 11, 1982, at 2, col. 3; Stewart, A Blue-Chip Law Firm Comes on Hard Times After a Coup d'Etat: Donovan Leisure Faces Risk Some Clients May Follow Top Partners in Leaving, Wall St. J., Nov. 18, 1983, at 1, col. 6; Galante, Jenkins E Perry Feud Almost Over, L.A. Daily J., Mar. 17, 1983, at 5, col. 1; Graham, Jacksonville Partners Win Control, Lose Colleagues, Legal Times, Apr. 5, 1982, at 2, col. 1 (discussing defections from Mahoney, Hadlow \& Adams); Moore, Houston's Butler, Binion Sees Biggest Split in City's History, Legal Times, Feb. 15, 1982, at I, col. 2; Graham, Progressive Ideals Put to Test at Wald, Harkrader, Legal Times Wash., Jan. 18, 1982, at 44, col. I.

6. One law firm analyst has stated the case against seniority-based systems as follows:

Any distribution system should operate to promote further harmony among the members of the firm and, at the same time, provide incentive to each. Any rigid system, such as one based strictly on length of time in the partnership, can operate to destroy incentive and in the long run will undoubtedly be detrimental to the firm operation.

Moldenhauer, Formula and Nonformula Systems for Distributing Partnership Net Income, 13 LAW OfF. Econ. \& MGMT. 21, 27 (1972). Similarly, Steven Brill, writing as a "consultant" to the Minneapolis firm Leonard, Street \& Deinard, cautioned:

Leonard, Street's 5:1 spread between highest and lowest partnership draws, based only on seniority, does not make sense. It's too much of a spread, and just basing it on seniority provides no incentive for partner productivity. I 
are promoted to partner or fired, ${ }^{7}$ are being challenged as inefficient. Stable organizational life within many firms seems to be a nostalgic memory of simpler times. ${ }^{8}$

Both the rapid growth and increased instability of law firms represent major changes in the character of organizations that provide the bulk of important types of legal services to important categories of commercial clients. The present inventory of theory bearing on law firm economics, however, cannot readily explain either phenomenon. Traditional economic theory suggests several reasons why larger firms may have cost advantages over smaller ones. These include economies of scale, ${ }^{9}$ returns to specialization, ${ }^{10}$ economies of scope, ${ }^{11}$ and minimum scale. ${ }^{12}$ While

would urge you to consider adding clients attracted, contributions to firm management, and hours actually billed to your criteria.

Brill, Memo to the Partnerships, AM. LAw., Nov. 1981, at 23, 27.

7. A number of firms, including, most prominently, Davis, Polk \& Wardwell, have considered or are actually experimenting with the creation of new categories of lawyers such as "permanent associates" or "salaried partners," as a way of retaining talented people who don't quite make partner, while addressing the profit squeeze engendered by rising overhead and shrinking associate-to-partner ratios. See Graham, New "Senior Attomey" Program Draws Attention at Davis Polk, Legal Times, Feb. 28, 1983, at 3, col. 1. See also Galante, Firms Look Closer at How to Create Lawyer Categories, L.A. Daily J., Aug. 22, 1983, at 1, col. 6; Hallam, Big Firms Search for Alternatives to Traditional Form, L.A. Daily J., Mar. 18, 1983, at 1, col. 5; Glasser, Firm Explores New Partnership Category, Legal Times, Feb. 14, 1983, at 12, col. 2 .

8. See Galante, Partners' Ranks Dwindle as Firms' Revenues Shrink, L.A. Daily J., Sept. 6, 1983, at 1, col. 4; Snider, Goodbye to the Good Life, L.A. LAw., Apr. 1983, at 14; Bernstein, Profit Pressures on the Big Law Firms, ForTune, Apr. 19, 1982, at 84; Couric, Changes Likely in Billings, Partner Draws, Legal Times Wash., Dec. 14, 1981, at 33, col. 4.

9. A single lawyer or small firm, for example, may be unable to utilize optimal amounts of such things as staff support (like secretaries, paralegals, and even associate lawyers) or hard assets (like word processing machinery, duplicating equipment, and library resources).

10. Real and significant efficiencies result from specialized expertise in a particular area of the law. An expert who has substantial experience in a legal specialty can often achieve, in a very short period of time, what would take novices much longer to accomplish.

11. These reflect not the savings from increased production of the same product, as in economies of scale, but, rather, the savings from the joint production of a number of different products. Consider, for example, the case of a firm that represents a large organization, such as a bank, with respect to some of the bank's activities. Once the lawyers in this firm have learned a great deal about the bank's organization, its personnel, and its policies, the firm should be able to provide the bank with other legal services that require the same information at a substantial cost advantage over potential competitors who would have to incur anew the costs of acquiring the information. The asset-information-can be used effectively in producing different types of legal services. See text accompanying note 75 infra. See generally Bailey \& Friedlander, Market Structure and Multiproduct Industries, 20 J. ECON. LITERATURE 1024 (1982); Teece, Towards an Economic Theory of the Multiproduct Firm, 3 J. Econ. Behav. \& ORGanization 39 (1982). 
plausible in theory, these explanations strike us as incomplete, whether considered singly or in combination. Nearly all of the returns to scale appear to be achievable by a firm much smaller than today's large law firms. ${ }^{13}$ Similarly, while efficiencies of spe-

12. This explanation for the existence of large law firms relates to the size of certain legal projects. Just as one small builder would be unable singlehandedly to construct a $\$ 100,000,000$ dam, so too would a small law firm be unable to undertake largescale litigation or a large corporate acquisition. Some legal work requires the coordinated efforts of many lawyers working together as a team. Like a "pick-up" basketball team, it is conceivable that "lead" counsel could simply pull together a group of independent practitioners in order to create a team of the necessary absolute scale. The attorneys for the plaintiffs in the "Agent Orange" litigation did just this:

Yannacone and Associates is a consortium of lawyers who banded together

for purposes of this lawsuit under the leadership of Victor Yannacone, who brought the initial actions and who was designated as lead counsel for the plaintiffs shortly after the cases were transferred to this court by the multidistrict panel. Some of the lawyers in the consortium represent plaintiffs in one or more of the component Agent Orange actions; others apparently have been brought into the group because of special expertise and experience. This case is too complex and too demanding for any single attorney to handle it on behalf of plaintiffs. Yannacone and Associates has already demonstrated that the combined efforts of its twenty or so members will fairly and adequately protect the interests of the class and that together they have the expertise and desire to prosecute this demanding action properly.

In re "Agent Orange" Product Liability Litigation, 506 F. Supp. 762, 788 n.32 (E.D.N.Y. 1980), cert. denied, 104 S. Ct. 1417 (1984).

The pulling together of a team of independent contractors for a specific project is, of course, the prevailing pattern in the construction industry, where a general contractor typically hires subcontractors on a job basis rather than maintaining its own crews on a full-time basis. See Eccles, The Quasifirm in the Construction Industry, 2 J. EcoN. BeHav. \& ORGANIZATION 335 (1981) (discussing the advantages of ad hoc organization in the construction industry).

13. The most striking characteristic of the economies of scale explanation-that firms grow to exhaust scale economies-is not that it is wrong, but that it does not seem sufficient to justify the increase in the number and size of very large firms. While capital expenditures may be "lumpy," it certainly does not take a very large organization to achieve the necessary scale for many of them. See Leibowitz \& Tollison, FreeRiding, Shirking, and Team Production in Legal Partnerships, 18 Econ. INQUIRY 380 (1980). One lawyer may not be able to use a secretary full time, but surely two or three can. Moreover, technology seems to be changing in a way that reduces substantially the size at which firms exhaust scale economies with respect to certain assets. The rapid drop in the price of personal computers, for example, now makes word processing equipment not very much more expensive than an electric typewriter was a few years ago. Furthermore, it would seem that sole practitioners can achieve a number of these gains by contracting among themselves as opposed to by creating or joining a firm. For example, sole practitioners or small firms can group together to create a law library or to share the costs of secretarial assistance or of a younger lawyer. Indeed, office sharing-by which sole practitioners share a considerable portion of their overhead, but not income-has long been a familiar phenomenon among sole practitioners. See text accompanying note $\mathbf{5 8}$ infra. Mforeover, the rapid computerization of much of the contents of a standard law library by services such as Lexis or Westlaw may substantially reduce the size of the capital 
cialization are real, and though the large law firm may well facilitate the development and maintenance of specialized expertise, ${ }^{\mathbf{1 4}}$ the existence of smaller "boutique" law firms plainly shows that specialization is possible regardless of firm size. Economies of scope may exist, particularly where information about a client is expensive to acquire, yet still is essential to the provision of legal services. It is unclear, however, why we should assume that it is the law firm and not the client that will capture these returns to scope. Finally, while some legal projects require the effort of a team of lawyers who may well achieve efficiencies if they work together on a regular basis, the size of the team necessary to achieve the minimum scale for even the largest legal projects seems hardly large enough to explain the absolute scale of today's large firm.

Similarly, familiar economic theory is of limited value in explaining the internal organization of law firms, let alone the current dissatisfaction with previously unquestioned traditions. What is styled the "theory of the firm" in the traditional economic literature is not a theory of the determinants of firm structure at all. It is rather a theory of how economic units compete in the market for goods or services. ${ }^{15}$ Indeed, in the past the question of the internal organization of law firms, and especially the critical issue of profit division, has been not only neglected by scholars, but veiled in silence.

Large firms have always had to divvy up profits among their partners. But like sex in marriage, dividing the partnership pie was until very recently one of those centrally important but awkward topics that intimates often had difficulty discussing with one another-“"Gentlemen" certainly did not talk about this issue

investment necessary for an adequate library. All of this is not to say that economies do not exist. Instead, we simply mean to suggest that they do not seem very difficult to achieve, can in fact be achieved by contract rather than through formation of a firm, and in any event, would hardly explain a cost advantage for a firm of 50 lawyers over a firm of 20 lawyers.

14. Specialization does involve something of a chicken/egg problem. To become a specialist requires a substantial investment in human capital and often takes an extended period of time. Once a person becomes a specialist, she can maintain her expertise, provided she can generate enough business. But absent an initial demand for the services, it is often difficult as a practical matter to develop the expertise. One explanation for the success of large law firms may well be that they are an efficient organizational form for the development and maintenance of specialized expertise.

15. See Jensen, Organization Theory and Methodology, 58 Accr. Rev. 319, 325-26 (1983). 
with outsiders, much less make public comparisons. In the past, everyone knew that dissatisfaction would occasionally lead lawyers to leave one firm and sometimes to start or join another. But such occurrences were rather rare, especially among lawyers in large, well-established firms, ${ }^{16}$ which were generally assumed to divide the pie by some sort of seniority-based system where a partner's share was largely determined by how long he had been a partner.

Times are obviously changing. In the popular press at least, yesterday's taboo has become today's fixation. Legal newspapers, consulting firms, and management journals now regularly offer advice on techniques that purport to facilitate long-term partnership bliss. Indeed, the American Lawyer recently sponsored for representatives of major law firms a closed (and very expensive) group therapy session on "Allocating Partner Shares and Assuring Partner Productivity ... In Today's New Legal Market."

Even this recent increase in attention to pie-division, however, has not led to a satisfactory explanation of the forces at work. There does seem to be a growing consensus among consultants and pundits that seniority-based systems are bad, and that a partner's share should depend primarily upon his or her productivity. It is claimed that the traditional method of pie-division deadens incentives and in the long run is inevitably detrimental to the firm's prosperity, stability, and survival. But despite the expert consensus concerning the right approach to pie-division, the observable facts present some troubling anomalies. Notwithstanding a substantial increase in open discussion of the delicate issue of pie-division and the availability of expert advice on the subject, the clearly observable fact is that partnership split-ups occur with increasing frequency, even among firms that claim to split the pie on the basis of productivity. Still more puzzling is the fact that several of the most successful large firms, including Cravath, Swaine \& Moore and Cleary, Gottlieb, Steen \& Hamilton, remain committed to a "lockstep," seniority-based system and appear to be more profitable than ever. If the consultants are right, what explains the continued prosperity of some

16. John Weil, a leading law firm consultant, recently declared that: "The founding father of a San Francisco firm left it recently when another firm made him an offer. Ten years ago he wouldn't even have considered doing such a thing. It would have been unprofessional." Waggoner, Dividing the Profit Pie, CAL. LAw., Jan. 1984, at 39, 41. 
large firms committed to a lockstep seniority system, and the instability of other firms that try to divide each year's profits by measuring the productivity of individual lawyers?

In this article, we shed new light on the internal organization of law firms and the relationship of organizational structure to changes in the market for legal services by showing how a law firm can provide the opportunity for individual lawyers to diversify the risks inherent in human capital. By looking at the problem in a new way, a new pattern appears. As with a kaleidoscope, no single pattern captures the entire reality. Altering the lens through which the subject is viewed, however, has the potential to illuminate otherwise hidden features. Thus, diversification provides an additional explanation for the existence of large law firms that has the advantage of focusing directly on the internal organization of such firms. We think it also explains both the commitment by a number of very successful large firms to the lockstep seniority system and the relationship between methods of income division and firm stability. In turn, recognition of the central importance of the method of income division in a law firm suggests a number of hypotheses concerning other important aspects of firm organization, including hiring and partnership selection policies. Our principal concern is thus to use a different theoretical framework to study an important social phenomenon-the large law firm. We also hope, however, that the application of this body of theory to a real world institution- "getting one's hands dirty"17 — will have the positive side effects of both extending the reach of the theory itself and helping to demonstrate its usefulness.

We begin in Part I by developing the framework that we use to analyze the corporate law firm. Our framework builds on the foundation of recent developments in two areas of economic theory: portfolio theory and the economic theory of agency. Portfolio theory reveals the potential gains from diversification that are available to individual lawyers who become members of a firm. The economic theory of agency, on the other hand, allows us to

17. Klein, Contracting Costs and Residual Claims: The Separation of Ownership and Control, 26 J.L. \& Econ. 367, 374 (1983). The need for careful examination of actual institutions is particularly important where, as here, there is reliance on an agency approach to organization. The transaction-cost orientation of this approach makes it quite easy to imagine a set of costs that would explain the constrained efficiency of any organization. See Klein, Transaction Cost Determinants of "Unfair" Contractual Arrangements, 70 AM. EcoN. REv. 356,362 (1980). 
identify three problems with sharing-temptations that may sometimes lead a firm to break up: shirking, a partner's failure to do his "fair share" of the work; grabbing, a partner's extraction of a larger than previously agreed share of firm profits by threatening to depart; and leaving, a partner's departure from the firm with clients and business in tow. Considered together, portfolio and agency theory explain an important source of gains from cooperation, as well as the barriers to cooperation that help dictate the form and structure of organizations formed to secure that gain.

In Part II we explore the central importance of a firm's method of income splitting. How a firm divides profits both reflects the extent to which it has captured the gains from diversification and reveals the internal performance incentives facing individual lawyers in the firm. We examine and compare two polar models of pie division: a seniority-based sharing model, which can best be understood in terms of our diversification analysis, and a productivity approach in which each partner's share is based upon his or her individual contribution to the firm's profits. We conclude that, contrary to the new conventional wisdom, because sharing facilitates diversification, the sharing model is superior, provided that shirking, grabbing, and leaving can be constrained. The next two parts then examine the circumstances that permit the happy congruence of diversification, stability, and productivity. In Part III we develop the concept of "firm-specific capital" to explain why successful firms committed to sharing remain stable, notwithstanding the risks of grabbing or leaving. In Part IV we investigate how a firm committed to sharing can reduce or avoid the risks of shirking, and in the process emphasize the importance of something as intangible as firm culture. Finally, in Part $V$ we consider the impact on the future of sharing of changes in the market for legal services.

\section{The Central Framework: The Law Firm Through the Lens of Portfolio and Agency Theory}

\section{A. Gains from Diversification}

The first step in understanding the dominance of large law firms is to understand the source of gains from cooperation among lawyers without regard, for the moment, to the character of the contractual arrangements by which they are achieved. Portfolio theory, a comparatively recent development in financial 
economics, provides significant insights into the source of these gains-and hence into the existence and structure of law firms. Portfolio theory is concerned with understanding what factors determine the value of a capital asset, a term which includes, for our purposes, the most critical element of legal practice: a lawyer's human capital. If portfolio theory can help us understand how to maximize the value of a lawyer's principal asset, it should go a long way toward identifying the opportunities for gain from cooperation that are peculiar to lawyers and, as a result, should provide important insights into the structure of law firms.

\section{Portfolio theory.}

The modern development of portfolio theory rests on the insight that risk averse investors will always hold a diversified "portfolio" of capital assets. ${ }^{18}$ This observation follows from two premises: (1) that investors prefer more return to less given the same level of risk, ${ }^{19}$ and (2) that investors prefer less risk to more given the same level of return. By combining assets in a portfolio, the investor can reduce the level of risk without reducing expected return. A rational investor will then select the portfolio of assets that offers the most desirable combination of risk and return.

The next point in the development of portfolio theory involves a closer look at what kind of risk is reduced by diversification. The overall risk associated with an asset's return is made up of two components, typically referred to as systematic and unsystematic risk. Systematic risk is that associated with holding any asset. Broad changes in economic conditions, such as increases or decreases in GNP or a change in the level of inflation, affect the value of all assets. By contrast, unsystematic risk is that associated with holding a particular asset. For example, if the capital asset in question is platinum, the risk that changes in defense technology will reduce the demand for platinum is unsystematic. By diversifying his portfolio, an investor can eliminate all unsys-

18. For a more detailed exposition of portfolio theory, see W. Sharpe, Portrolio Theory and Capital Markets (1970); see also R. Brealey \& S. Meyers, Principles of Corporate Finance 112-56 (1981); J. Van Horne, Financial Management and Policy 49-77 (5th ed. 1980).

19. In this context, risk is treated as the likelihood that an actual outcome will vary from the expected outcome. See, e.g., R. BREaley \& S. MeYers, supra note 18, at 112-18; J. VAN HoRNE, supra note 18, at 33-36; see also W. SHARPE, INVESTMENTs 119-22 (2d ed. $1981)$. 
tematic risk. So long as the portfolio contains a sufficient number of assets, the impact of an event that lowers the value of one asset will be balanced both by the same event's favorable impact on other assets in the portfolio and by the occurrence of other events affecting other assets. Consequently, on balance there will be no effect on the value of the portfolio as a whole. A fully diversified portfolio is thus simply not subject to unsystematic risk. ${ }^{20}$ The only risk that remains in a diversified portfolio, then, is systematic risk - the risk of events that will alter the value of all assets.

The final point in the development of portfolio theory for our purposes involves the recognition that the market pays no premium to investors who bear avoidable risk. The return on, and therefore the price of, a capital asset will depend on how much systematic risk is associated with it. ${ }^{21}$ If the asset carries a great deal of systematic risk-if it is quite responsive to general economic conditions-an investor will require a higher return, and the asset will warrant a lower price, than would an asset that is less sensitive.

To see that differences in unsystematic risk will not affect the value of an asset, suppose that a public utility intends to issue common stock on the basis of competitive bids: The highest bid-i.e., the lowest return to the investor-will succeed. Further suppose that there are two bidders, one who already holds a diversified portfolio of investments and one who does not. Because the diversified bidder would bear less risk than the undiversified investor but would still receive the same return, the stock would be worth more to him: He would be able to offer a higher bid. The value of an asset is thus set on the basis of its value to a diversified investor. As a result, the undiversified investor will receive no return for bearing unsystematic risk.

20. See, e.g., R. Brealey \& S. Meyers, supra note 18, at 119-21; J. Van Horne, supra note 18, at 61-64; Modigliani \& Pogue, An Introduction to Risk and Return: Concepts and Evidence, Fin. Analysts J., Mar.-Apr. 1974, at 68, 73-76.

21. The statement in the text reflects the standard two-parameter capital asset pricing model in which the only factors that bear on asset value are risk and return. This approach has been criticized recently for a number of reasons, see generally, Ross, The Current Status of the Capital Asset Pricing Model (CAPM), 33 J. FIN. 885 (1978), particularly because the relevant empirical evidence does not clearly establish that risk and return are the only factors that bear on asset value. See, e.g., W. SHARPE, supra note 19, at 175-84. For our purposes, however, the resolution of this debate is not critical. All that is necessary to our analysis is that there be gains from eliminating unsystematic risk: We need not rely on the stronger claim that only systematic risk determines value. 
We believe this fact-that capital assets are of greater value when held by a diversified investor-is crucial to understanding why law firms exist at all and why they take their familiar form. Once we recognize that a lawyer's most important asset is his human capital, portfolio theory's emphasis on diversification highlights a critical characteristic about this asset: It is very difficult to diversify an investment in human capital. Significant elements of law firm organization, we will argue, result from both the effort to diversify and the difficulty of doing so effectively.

\section{The critical role of human capital.}

The organizational structure of large law firms can be illuminated by recognizing that for an individual lawyer the ability to earn money as a lawyer is a capital asset-one whose value depends on its ability to produce income in the future. ${ }^{22}$ The ability to practice law is the observable manifestation of the lawyer's human capital: The lawyer has invested time and money in acquiring skills that allow him to render valuable services. A lawyer's earnings thus represent the return on his investment in human capital. Once it is recognized that the ability to practice law is a capital asset, portfolio theory becomes relevant to understanding how to maximize that asset's value. The problem, however, is the special character of the lawyer's principal capital asset: A lawyer earns a return on his investment only by actually rendering services. This makes it difficult to implement the answer that portfolio theory provides: the elimination of unsystematic risk through diversification. Our analysis suggests that the large law firm is a response to this difficulty.

Earnings from the practice of law, like returns from other capital assets, are subject to two different kinds of risks: systematic and unsystematic. For purposes of the lawyer's human capital, systematic risk is the extent to which earnings from the practice of law vary with overall economic conditions: How sensitive are a lawyer's earnings to the performance of the economy? Unsystematic risk, in contrast, is the variation in earnings from law practice resulting from the individual characteristics of a particu-

22. Law practice may have consumption value in addition to its value in producing income. For example, the social status associated with being a lawyer may provide utility independent of income. So long as the investment value predominates, which we think an uncontroversial assumption at least for lawyers joining large law firms, this does not alter our analysis. 
lar lawyer: For example, how smart, attractive to clients, healthy, and long-lived is a particular lawyer? Portfolio theory teaches that investors do not earn a return for bearing the unsystematic risk associated with a capital asset because that risk can be eliminated by diversification. For that reason, a stockholder in a publicly held company may be unconcerned with the health of the company's president, for although the fortuity of the president's ill health might have an impact on the performance of the company, it would have no impact on the return of a diversified portfolio, one of whose holdings was the company's stock. By way of contrast, a lawyer's ill health has a substantial impact on his earnings precisely because it is extremely difficult to diversify one's human capital. ${ }^{23}$

The inability of a lawyer to diversify away unsystematic risk does not, of course, leave the lawyer entirely at the mercy of fate. Some elements of unsystematic risk, such as death or disability, can be diversified through insurance markets. ${ }^{24}$ But insurance markets do not exist for other important aspects of the unsystematic risk associated with a lawyer's human capital. Most importantly, the lawyer can neither sell his human capital at the start of his career for its expected value nor insure against the risk that he will turn out to be less successful than his expectations. There are also other events which, like disability, reduce the returns from the lawyer's human capital, but which, unlike disability, are essentially uninsurable. Practitioners are familiar with the impact on earnings of upheavals in a lawyer's personal life-like divorce, mid-life crisis, or alcoholism-that for an often

23. Most importantly, it would take a substantial amount of ordinary capital to diversify a young lawyer's human capital. For example, consider the circumstance of a 40year-old lawyer with an expected remaining professional life of 25 years and an expected annual earnings net of inflation of $\$ 125,000$ per year. The present value of that income stream exceeds $\$ 1,250,000$, even assuming a $10 \%$ discount rate, which is likely too high when inflation is ignored. Twenty-seven students in a Stanford Law School estate planning class were asked to calculate the net present value of their expected future earnings as lawyers. The average estimate exceeded $\$ 2,000,000$. Diversifying a single investment of that size would require a significant multiple of that amount.

24. The effect of insurance is to create a two asset portfolio in which the values of the two assets vary in precisely opposite directions. For a lawyer whose human capital is worth $\$ 1,250,000$, ownership of a $\$ 1,250,000$ term life insurance policy means that death no longer affects the lawyer"s "net worth." If the lawyer does not die, his human capital is worth $\$ 1,250,000$, and the insurance policy is worth nothing; if he dies, his human capital becomes worthless, but the insurance policy is then worth $\$ 1,250,000$. The value of the two-asset portfolio is thus invariant to the lawyer's death: Its risk has been eliminated by diversification. 
substantial period of time can significantly reduce the lawyer's productivity. It is hardly surprising that insurance markets do not exist for these risks. These risks share the twin problems of adverse selection and moral hazard that combine to make traditional insurance infeasible. ${ }^{25}$ Because it is difficult to determine ex ante the "real" expected value of a lawyer's human capitalthe probability distribution that best describes the lawyer's future earnings-it also will be difficult to determine the appropriate premium for insurance against ex post variation from that value. And if the "real" expected value of the lawyer's human capital is, as one would expect, more easily observed by the lawyer than by the insurance company, the standard adverse selection problem would arise. A rate that reflected the average deviation would attract those lawyers who knew they were a worse than average risk and repel lawyers who knew they were a better than average risk. The same problem-the real risk's being more easily observed by the lawyer than by the insurance company-is also present with respect to the special disability-like events we mentioned. Of equal importance, insurance against either riskagainst a lower than expected return on the lawyer's human capital, or against the occurrence of one of the disability-like eventspresents serious moral hazard problems. Determining whether the event insured against has really occurred, or whether the lawyer has merely determined that collecting the insurance proceeds is preferable to continuing to work, requires a level of observation and monitoring of individual insureds that is inconsistent with a workable insurance market.

From the perspective of portfolio theory, then, the fact that a lawyer's human capital is difficult to diversify, together with the fact that insurance markets are unlikely to develop with respect to important elements of unsystematic risk bearing on the lawyer's human capital, mean that an opportunity exists for the emergence of an institution to fill this gap-to enable lawyers to capture the gains from diversifying their human capital. We think that much can be learned about the existence and organization of large law firms from understanding how they might serve this function. To be sure, the question of why the gap is filled by a firm rather than by contract between independent practitioners remains. Before considering this question in Part $\mathrm{IB}$, however,

25. See, e.g., Rothschild \& Stiglitz, Equilibrium in Competitive Insurance Markets: An Essay on the Economics of Imperfect Information, 90 Q.J. EcoN. 629 (1976). 
we will attempt to demonstrate how law firms, by facilitating specialization, provide a different kind of opportunity to diversify.

\section{Diversification and specialization.}

Recognizing that a lawyer's human capital is difficult to diversify offers significant insights into a lawyer's decision to specialize. The problem caused by the inability to diversify is that the lawyer bears too much risk. In this context, specialization only makes matters worse. By narrowing the lawyer's human capital investment even further, the extent of unsystematic risk associated with the investment's return increases: The level of returns from a specialized practice, while higher than that from a general practice, is likely to vary more substantially.

The problem is best understood through an example. Imagine that a lawyer is considering making the investment in human capital necessary to become either a securities lawyer, specializing in venture capital placements, or a bankruptcy lawyer, specializing in reorganizations. Further imagine that the investments in human capital necessary to achieve each specialty are identical, and that they are mutually exclusive. ${ }^{26}$ The lawyer believes that the expected return on an investment in becoming a securities lawyer will depend on the performance of the stock market. His expectations of that return and its relationship to stock market performance are as follows:

\begin{tabular}{lcc}
$\begin{array}{l}\text { Stock Market } \\
\text { Performance }\end{array}$ & $\begin{array}{c}\text { Probability } \\
\text { of Occurrence }\end{array}$ & $\begin{array}{c}\text { Additional } \\
\text { Earnings as a } \\
\text { Securities Lawyer }\end{array}$ \\
\hline Bull market & $1 / 3$ & $\$ 200,000$ \\
Flat market & $1 / 3$ & $\$ 100,000$ \\
Bear market & $1 / 3$ & $\$ 0$
\end{tabular}

Similar analysis of the expected returns from a bankruptcy specialty shows that these will also vary with stock market performance but in exactly the opposite direction, presumably because, in contrast to a securities practice, bad economic times-resulting in a bear market-mean good times for a bankruptcy lawyer. ${ }^{27}$ Accordingly, the lawyer believes that the returns

26. The assumption of exclusivity, of course, is somewhat artificial. Lawyers frequently have more than one specialty. Where there is a sufficient overlap between the specialties, such as secured transactions and bankruptcy, there may be economies of scope associated with their combination.

27. We recognize that the relationship between a venture capital practice and a 
associated with an investment in bankruptcy skills would be as follows:

\begin{tabular}{lcc}
$\begin{array}{l}\text { Stock Market } \\
\text { Performance }\end{array}$ & $\begin{array}{c}\text { Probability } \\
\text { of Occurrence }\end{array}$ & $\begin{array}{c}\text { Additional } \\
\text { Earnings as a } \\
\text { Bankruptcy Lawyer }\end{array}$ \\
\hline Bull market & $1 / 3$ & $\$ 0$ \\
Flat market & $1 / 3$ & $\$ 100,000$ \\
Bear market & $1 / 3$ & $\$ 200,000$
\end{tabular}

Analysis of both tables indicates that an investment in either securities law or bankruptcy law expertise has an identical expected return: earnings of $\$ 100,000$. Both investments, however, present substantial risk; there is a $1 / 3$ probability that the lawyer would earn no return at all on either investment.

This risk, however, could be diversified away, as demonstrated in the following table, if the lawyer somehow could put one-half of his investment in each specialty.

\begin{tabular}{lclll} 
& & $\begin{array}{l}\text { Half } \\
\text { Additional } \\
\text { Earnings } \\
\text { as a }\end{array}$ & $\begin{array}{l}\text { Half } \\
\text { Additional } \\
\text { Earnings } \\
\text { as a }\end{array}$ & \\
$\begin{array}{l}\text { Stock } \\
\text { Market }\end{array}$ & $\begin{array}{l}\text { Probability } \\
\text { of Event }\end{array}$ & $\begin{array}{l}\text { Securities } \\
\text { Lawyer }\end{array}$ & $\begin{array}{l}\text { Bankruptcy } \\
\text { Lawyer }\end{array}$ & $\begin{array}{l}\text { Portfolio } \\
\text { Earnings }\end{array}$ \\
\hline $\begin{array}{lcccc}\text { Performance } \\
\text { Bull Market }\end{array}$ & $1 / 3$ & $\$ 100,000$ & $\$ 0$ & $\$ 100,000$ \\
Flat Market & $1 / 3$ & $\$ 50,000$ & $\$ 50,000$ & $\$ 100,000$ \\
Bear Market & $1 / 3$ & $\$ 0$ & $\$ 100,000$ & $\$ 100,000$
\end{tabular}

Because the returns on an investment is expertise in securities law and bankruptcy law respond in exactly opposite ways to the performance of the stock market, the risks associated with future stock market performance are entirely eliminated-diversified away-by holding a portfolio composed of equal investments in both forms of human capital. The problem, however, is apparent. The lawyer cannot diversify his human capital investment. He cannot be both a securities law specialist and a bankruptcy

bankruptcy practice described in the text, while rhetorically helpful, may in reality be inaccurate. Returns to a bankruptcy practice may well lag the business cycle because only as poor conditions continue would businesses be forced into bankruptcy. In contrast, a venture capital practice may even anticipate an upturn in the business cycle so that, in fact, movements in the value of the two types of practice at times might well be parallel. Certainly the concurrent boom in both specialties that the profession has recently experienced lends credence to this analysis. 
law specialist. Nor is there a traditional market by which he can sell a portion of his returns from one specialty and use the proceeds to purchase an interest in the other. ${ }^{28}$

Analysis of a lawyer's human capital investment in specialization from the perspective of portfolio theory thus demonstrates again both an opportunity to increase the value of that capital through diversification and the absence of any readily available means by which the lawyer can accomplish it. Indeed, the historical pattern of increasing specialization in the legal profession ${ }^{29}$ suggests that the opportunity may be quite substantial. And, as with diversification of the risks considered in the previous subsection, the creation of a full-service law firm-an agreement among lawyers that each will make human capital investments in different specialties and that the returns to those investments will be shared on a predetermined basis rather than in accordance with actual outcomes-can be understood as an institutional innovation that allows lawyers to take advantage of gains from diversification. ${ }^{30}$

28. A similar analysis is possible with respect to industry, as opposed to legal, specialization. As our colleague Lawrence Friedman has called to our attention, where a lawyer has invested a great deal in obtaining extensive factual knowledge about an industry, that investment is subject to the same kind of risk as is an investment in knowledge about the special legal rules bearing on that industry.

29. For example, in his study of four large Chicago law firms, Nelson notes that even in the firm with the lowest incidence of specialization, some $90 \%$ of the lawyers described themselves as specialists. Nelson, The Changing Structure of Opportunity: Recruitment and Careers in Large Law Firms, 1983 Am. B. Found. Research J. 109, 131.

30. The development of the law firm does not, however, entirely solve the problem of diversifying a lawyer's human capital: While a partner in a law firm might, depending on the manner in which profits are split, see note 52 infra, hold a diversified portfolio with respect to the legal industry, complete diversification would require diversifying into other industries as well. The problem facing a lawyer is thus conceptually no different from that of the owner of any closely held business. Diversification for such an owner might be achieved by going public-selling a portion of the business to others in order to acquire the liquid assets necessary for diversification. From this vantage point the puzzle is why large law firms have not taken advantage of this solution: Why has Cravath not gone public?

The short answer, of course, is that state law typically prohibits nonlawyer shareholders in corporations rendering legal services. In California, for example, both the State Bar Act, Cal. Bus. \& Prof. Code $\$ 6165$ (West 1974), and the Professional Corporations Act, CAL. CORP. CODE $\S 13406$ (West 1977), limit stock ownership to licensed professionals. This answer, however, only shifts the inquiry to explaining why the prohibition continues in light of the influence of lawyers on the relevant legislation.

While this is not the occasion to review the variety of potential historical explanations for the absence of publicly held law firms, or the plethora of technical problems associated with divided loyalties between client and shareholder and conflicting responsibilities of confidentiality to clients and disclosure to shareholders, it is worth noting 


\section{B. Barriers to Capturing the Gains from Diversification: Shirking, Grabbing, and Leaving}

Our analysis thus far has demonstrated one fact and asserted a second. We have shown that the difficulty of diversifying a law-

that the economic explanations that have been offered to date are not persuasive. Fama and Jensen have argued in two recent articles that ownership in law firms is limited to lawyers active in the practice because decision management and decision control cannot be separated. In essence, they believe that no one, not even another lawyer, can successfully monitor lawyers' performance. As a result, only an interest in profits can constrain shirking. See Fama \& Jensen, Separation of Ownership and Control, 26 J.L. \& Econ. 301, 315-17 (1983); Fama \& Jensen, Agency Problems and Residual Claims, 26 J.L. \& Econ. 327, 334-36 (1983) [hereinafter cited as Fama \& Jensen, Agency Problems]. The difficulty with this argument is its premise-that decisionmaking in law firms cannot be effectively supervised. While day-to-day decisions concerning a particular lawsuit or transaction may not be subject to the formal controls Fama and Jensen have in mind, the larger decisions-the significant strategic choices concerning a matter-seem no more difficult to subject to formal controls than are decisions concerning competitive strategy in any business. Moreover, even the agency costs associated with the smaller decisions can be constrained through "ex post settling up"-the potential for the imposition of a bonus or penalty depending on how the decisions turn out. Indeed, Fama makes precisely this claim with respect to managerial decisionmaking. See Fama, Agency Problems and the Theory of the Firm, $88 \mathrm{~J}$. PoL. ECON. 288 (1980). In this regard, the "professional" character of a lawyer's work is hardly a convincing distinction in the face of publicly held advertising agencies and engineering firms.

Oliver Williamson offers an alternative explanation for the absence of publicly held law firms. He argues that the value of the firm depends on its special information concerning clients. Because it is neither possible to separate the information from the individuals who possess it, nor to keep these individuals from leaving the firm with it, there is really nothing to sell to the public. Williamson, Organization Form, Residual Claimants, and Corporate Control, 26 J.L. \& ECoN. 351, 358 (1983).

Here again, the problem with the argument is its sweeping premise. As we demonstrate below, see text accompanying notes 65-66 infra, significant elements of firm value cannot be appropriated by an individual lawyer who leaves the firm. At least in theory it should therefore be available for sale. The successful public offerings of advertising agencies-which would also seem to present the characteristics that Williamson stresses with respect to law firms-serve to support this analysis. To be sure, the price would reflect the risks associated with the value of law firms, in part because of the problem Williamson identifies. One would expect shares of companies with respect to which personal services were important to sell at lower price-earnings ratios than do those for which hard assets are central.

A more promising inquiry concerns what happens to the firm following a public offering. Partners at the time of the offering would share in the proceeds from the sale of firm specific capital. The problem, however, arises with respect to those who are not yet partners: How do they diversify their human capital in the absence of the returns from firm specific capital that we argue, see text accompanying notes 65-66 infra, are necessary to enforce the sharing bargain? An examination of the compensation structure of legal organizations which are, in an important sense, already publicly held law firms-the large in-house law firms now found in many corporations-may provide important clues. We speculate that there the opportunity to diversify is provided through stock options-an interest in the diversified stream of income of the entire enterprise. If this speculation is correct, we would expect that the timing of participation in stock 
yer's human capital investment creates an opportunity for the development of an institution that would facilitate diversification. But thus far we have only asserted that the development of the large law firm responds to this opportunity. An additional perspective is necessary to turn that assertion into an analysis detailed enough to allow us to evaluate the claim that the law firm is an organizational innovation which serves to facilitate the diversification of human capital.

The need for a second look is apparent when we consider what happens to a lawyer's view of the gains from diversification between the time he agrees to share his future income in order to benefit from diversification and the time when the agreement will be performed-when the lawyer favored by fate actually must share his earnings with a colleague in a less profitable specialty. At the time the two initially agree to share, the future is uncertain: Both stand to gain from an agreement to pool their future earnings. The situation changes markedly, however, when the passage of time eliminates the risk. In our example of a securities lawyer and a bankruptcy lawyer, time will reveal whether the stock market will be bull, flat, or bear, and, hence, whether it is the securities or the bankruptcy lawyer that has won the right to share his good fortune with the loser. At this point, the winner may refuse to comply with his original bargain: $\mathrm{He}$ no longer has anything to gain by sharing. The potential for individuals to pursue their own self-interest-in our setting, to thwart diversification-and the role of organizational structure as a means of constraining it is the province of agency theory, a second recent development in economic theory that we believe can be useful in explaining law firm organization. Understanding the law firm as a means of capturing the gains from diversification requires understanding how it prevents self-interested behavior from interfering.

option plans for in-house lawyers would resemble the path toward partnership in a law firm.

A somewhat analogous problem may have arisen when a publicly held corporation acquired Salomon Brothers, a major investment banking partnership. In effect, the transaction was a public offering by the then Salomon partners. It would be particularly interesting to examine the post-acquisition compensation arrangements for Salomon employees who were previously on the partnership track.

If there is no economic reason for the absence of publicly held law firms-if the explanation proves to be historical and cultural-then the future may yet hold some surprises. 
1. Agency theory.

While portfolio theory identifies an important source of gains from cooperation among lawyers, agency theory highlights the barriers to capturing these gains and the methods by which these barriers can be partially, but never entirely, surmounted.

A simple example will illuminate the problem. Suppose we need a particular piece of work done for which we lack either the time, the skills, or the information to do it ourselves. An intuitively sensible reaction would be to hire someone to do the work for us. The problem with this solution, however, is that while there is a potential for both sides to benefit from cooperation, our interests and those of the individual that we hire are not identical. We want the task done well and at as low a price as possible. Our agent, in contrast, will want the greatest pay for the least effort. The value of the agent to us-and the potential for realizing gains from cooperation-then turns on the extent to which we can devise a relationship which causes the agent's incentives to be compatible with our own. ${ }^{31}$

With this in mind, it is only a short step-at least conceptually-from a simple two-party problem to a theory of organization. If we look at an organization at the level of the individual, it appears as a nexus of contracts-formal and informal-pursuant to which each individual contributes his factor of productionlabor, capital, or tangible asset-to a cooperative enterprise in order to achieve greater returns on the factor than would be available independently. ${ }^{32}$ In a public corporation, for example,

31. The agency literature, while of relatively recent origin, is by now quite substantial. For descriptive purposes, it can be broken down into two categories: what Michael Jensen has labeled the "positive theory of agency," and the principal-agent literature. Jensen, supra note 15, at 334. While both address a common problem-the difficulties of contracting between individuals who maximize their own self-interest-the positive theory of agency has emphasized the impact of a wide variety of factors, such as bonding and monitoring techniques, on the contracting problem. See, e.g., Smith \& Warner, On Financial Contracting: An Analysis of Bond Covenants, $7 \mathrm{~J}$. Fin. Econ. 117 (1979); Williamson, Credible Commitments: Using Hostages to Support Exchange, 73 AM. Econ. Rev. 519 (1983) [hereinafter cited as Williamson, Credible Commitments]. The principal-agent literature has concentrated on the development of formal mathematical models of the impact of risk preferences and information asymmetries on the design of optimal contracts. See, e.g., Harris \& Raviv, Optimal Incentive Contracts with Imperfect Information, 20 J. ECON. THEORY 231 (1979); Ross, The Economic Theory of Agency: The Principal's Problem, 63 AM. Econ. Rev. Papers \& Proc. 134 (1973); Shavell, Risk Sharing and Incentives in the Principal and Agent Relationship, 10 BELL J. ECON. 55 (1979).

32. Jensen \& Meckling, Theory of the Firm: Managerial Behavior, Agency Costs and Ownership Structure, 3 J. Fin. EcoN. 305 (1976), is generally treated as the source of the nexus 
shareholders who lack managerial skills but have wealth contribute their capital; managers who possess skills but not wealth contribute their talents; workers contribute their labor; and so on, all according to explicit or implicit bargains governing the nature of their contributions and the character of their returns. Organizations are thus simply complex aggregations of cooperative relationships entered into on the belief that gains will result.

But just as complex organizations result from the same motive as the simple two-person relationship with which we began, so too do organizations share, on a more complex basis, the same barriers to achieving the gains from cooperation present in the simple situation. The potential for each participant in the organization to maximize his self-interest at the expense of that of the other participants-to cheat on the terms of his bargain-can greatly reduce or even eliminate the potential for gain from organization. An agency theory of organization focuses on how organizations maximize the gains from cooperation by adopting structures which reduce the potential for participants to pursue their individual, rather than their collective, self-interest. ${ }^{33}$

The final step in this brief primer is to consider the nature of the barriers which constrain efforts to eliminate self-interested behavior in organizations. Imagine for a moment a Coasean world in which there are no transaction costs. In this world: (1) information is free; (2) complicated contingent contracts, which specify the performance expected of each individual in all

of contracts approach to the firm. Jensen and Meckling in turn stress the pioneering work of Ronald Coase, The Nature of the Firm, 4 Economica 386 (1937). From the perspective of intellectual history, it is somewhat difficult to understand the relationship between the positive theory of agency, identified with Jensen and Meckling, and transaction cost economics, identified with Oliver Williamson. See, e.g., O. Williamson, MarKETS AND HIERARCHIES: ANALYSIS AND ANTTTRUST Implications (1975) [hereinafter cited as O. Williamson, Markets and Hierarchies]; Williamson, Transaction-Cost Economics: The Governance of Contractual Relations, 22 J. L. \& Econ. 233 (1979). Although both have developed distinctive vocabularies, and although agency may be characterized as emphasizing relationships within the firm while transaction cost economics stresses the question of when particular transactions occur across markets or within a firm, the difference in descriptive titles ignores the almost complete overlap in problems of interest and analytic approach. We use the agency terminology here only because it is more narrowly descriptive of our particular concern-the internal organization of law firmsthan are the more general notions of transaction cost economics.

The principal-agent literature has only recently emphasized the multi-agent, as opposed to the single agent, problems that characterize firm organization. See, e.g., Holmstrom, Moral Hazard in Teams, 13 BeLl J. Econ. 324 (1982); Marcus, Risk Sharing and the Theory of the Firm, 13 BELL J. ECON. 369 (1982).

33. See Jensen, supra note 15; Jensen \& Meckling, supra note 32. 
possible future states of the world, can be costlessly written; (3) the actual performance of individuals can be costlessly monitored-that is, compared to their promised performance; and, (4) when actual performance does not measure up, the terms of the bargain can be costlessly enforced. In such a world, individuals in organizations would have no incentive to behave in a selfserving manner because any deviation from the behavior fully specified in the bargain would be costlessly identified and remedied. Where there are transaction costs, however, the individual is to that extent free to pursue his self-interest despite the terms of his bargain, and the gains from cooperation are to that extent reduced. An agency theory of organization seeks to explain organizational form as an effort to reduce the costs of cooperation: the "agency costs" of techniques designed to restrain self-serving behavior and hold agents to the terms of their bargains. ${ }^{34}$ Producers benefit from lower costs, thus, incentives exist for organizations to adopt a form which most effectively reduces agency costs and therefore most effectively captures the gains available from cooperation. ${ }^{35}$

2. The interface of portfolio and agency theory in the law firm: ex post cheating on the ex ante sharing bargain.

Applying portfolio theory to lawyers' human capital identified the opportunity to increase the value of this capital through diversification, i.e., by an agreement among a number of lawyers to share earnings. Agency theory, however, stresses that self-interested individuals have substantial incentives to renege on their obligations once the relevant uncertainties have been resolved by time, and treats the choice of organizational form as an effort to minimize the cost of holding the parties to the terms of their bargains. In addition to affecting the level of gains from diversification, selection of organization form may also affect the level of agency costs. A law firm whose organizational form minimizes these agency costs will have a competitive advantage.

This competitive advantage can be seen by reference to our securities lawyer-bankruptcy lawyer example. In the example, expected additional earnings of $\$ 100,000$ were necessary to per-

34. See, e.g., Jensen, supra note 15, at 331-32; Jensen \& Meckling, supra note 32, at 308-10; Klein, Contracting Costs, supra note 17, at 373-74; Williamson, The Modern Corporation: Origins, Evolution, Attributes, $19 \mathrm{~J}$. ECON. Literature 1537, 1543 (1981).

35. See Jensen, supra note 15, at 331-32. 
suade a lawyer to invest in specialized human capital. But how must an undiversified lawyer price his services in light of the uncertainty associated with the expected earnings? An effectively diversified securities lawyer-one who has entered into a sharing agreement with a bankruptcy lawyer-bears less risk than an undiversified securities lawyer but receives the same return. The diversified lawyer should be able to underbid his undiversified competitor in an auction for the opportunity to render legal services. ${ }^{36}$

The importance of organizational form to enforcement of the sharing bargain, and the clear superiority of the law firm, as opposed to an income-sharing contract between independent practitioners, as an enforcement vehicle, can be seen by examining two polar cases: one in which the sharing bargain is legally enforceable and one in which it is not. The juxtaposition of these two cases is of particular significance because one polar casethe world of unenforceability-in fact describes the real world.

\section{A hypothetical world in which the sharing bargain is legally enforceable.}

In a world in which sharing bargains were legally enforceable, organizational form would be irrelevant. First consider the extreme. Imagine a world where a contract between independent practitioners to share income would be enforceable by specific performance. If the securities lawyer in our example proved to be in the more profitable specialty, he could be forced to remain in the practice of securities law and share his earnings with the bankruptcy lawyer. Less extreme but more plausible might be a remedy where the bargain that was reflected in the organization of a law firm would be enforced by means of a long-term covenant not to compete. Use of such a covenant would assure that

36. Considered from the perspective of the firm, the shorter the useful life of a legal specialty, the smaller the output over which the investment in specialized capital can be recovered, the higher the necessary unit price. A firm which is limited to a single specialty bears the risk that its entire specialized capital will lose its value and, thus, the firm must price its product accordingly. This risk is significantly reduced in a diversified firm-one that has invested in a variety of specialties-because any event that decreases the value of one specialty likely will increase the value of another, leaving the overall return on the firm's specialized capital unchanged. Because the diversified firm does not bear the risk of obsolescence with respect to a particular specialty-that risk is eliminated through diversification-it need not charge a premium that takes this risk into account. As a result, one would expect that the unit price diversified firms charge for any specialty would be lower than that charged by undiversified-boutique-firms. 
the returns from the securities lawyer's alternative uses for his human capital would be sufficiently lower than the returns available from his capital's employment within the firm, even after sharing, that the incentive to renege on the sharing bargain would be eliminated.

In this world of perfect enforcement, organizational form is largely irrelevant to the maximization of gains from diversification because the problem of ex post opportunism has been assumed away. ${ }^{37}$ To be sure, agency problems are not eliminated by perfect enforcement. They do, however, change in important ways. When the securities lawyer does not receive all of the returns from his effort, there is an incentive to shirk-to work less hard than would be the case were he allowed to keep all of the returns. In this sense, an enforceable sharing bargain reduces the securities lawyer's wages compared to a world in which he is allowed to keep it all; and a decrease in price simply leads to a decrease in supply. The result of eliminating the agency problem of reneging on the sharing bargain through enforcement is thus to replace it with the agency problem of shirking. But the role of organizational form as a device to constrain shirking seems quite small. Profit sharing ${ }^{38}$ cannot work since it is precisely the requirement to share that creates the problem. A system of profit sharing that seeks to overcome the shirking problem by allocating profits on the basis of productivity would be flatly inconsistent with achieving gains from diversification, unless it were possible to distinguish between reduced productivity resulting from shirking and reduced productivity resulting from the occurrence of one of the events the risk of which diversification was intended to eliminate.

One would thus expect that constraints on shirking in a world of perfect enforcement would focus on measuring the number of hours worked-the typical law firm time-keeping system. ${ }^{39}$ Such

37. The problem might take on greater importance were the costs of assuring specific performance of a contractual sharing bargain significantly different from the costs of enforcing a covenant not to compete.

38. See Alchian \& Demsetz, Production, Information Costs, and Economic Organization, 62 AM. ECoN. REv. 777 (1972).

39. What literature there is suggests that monitoring hours worked is sufficient to resolve the shirking problem. See, e.g., Leibowitz \& Tollison, supra note 13, at 382; McChesney, Team Production, Monitoring, and Profit Sharing in Law Firms: An Alternative Hypothesis, 11 J. LEGAL STUD. 379, 382-87 (1982) (collecting empirical evidence of pervasive monitoring by law firms of hours worked by individual lawyers). The difficulty, however, is that shirking is more than a problem of not putting in enough hours; the more difficult 
a system would not be entirely devoid of significance for organizational form. The need to monitor attorney behavior in order to discourage falsification of time records would counsel in favor of maintaining physical proximity among the productive lawyer and the objects of his beneficence. This need for physical proximity in turn creates opportunities for economies of scale in support staff, library, and office space. The result is that the actual relationships among independent practitioners who engage in a contractual sharing bargain might appear to be indistinguishable from the relationships among lawyers who implement the sharing bargain by organizing a firm. At that point, of course, the distinction becomes irrelevant because the term "firm" is merely a shorthand for a particular cluster of contractual relations among the participants. ${ }^{40}$

This analysis suggests that the law firm would dominate simple contractual relations as a means of implementing a sharing bargain because the need to monitor against shirking may create the potential for economies of scale. The need to facilitate monitoring, however, provides little in the way of explanation for the peculiar characteristics of law firms that we hope to explain. And it is the very insignificance of organizational form in a world of perfect enforcement that in turn suggests that it may take on major importance where the sharing bargain cannot be legally enforced. That, of course, is the world in which we live. Specific enforcement of employment obligations is not available in the real world and covenants not to compete among lawyers are not enforceable. ${ }^{41}$ In this world, the agency problem is to devise nonlegal constraints on ex post opportunism. It is this function that we think provides interesting insights into the internal structure of large law firms.

aspect arises with respect to lawyers who put in their time, but do not try hard enough to be effective. Monitoring this level of effort is quite difficult. We consider this more difficult aspect of shirking in Part IV, see note 101 infra and accompanying text, and argue that it in fact has important implications for law firm organization.

40. See Alchian \& Demsetz, supra note 38, at 783; Jensen, supra note 15 , at 326-28.

41. For example, the Rules of Professional Conduct of the State Bar of California, which have the force of law under the State Bar Act, CAL. Bus. \& PROF. CoDE $§ 6077$ (West 1974), prohibit partnership agreements that restrict the right of a lawyer to practice law after his withdrawal from the partnership. California Rules of Professional Conduct 2-109 (1974); see American Bar Association, Model Code of Professional RESPONSIBILITY, DR 2-108 (1982). This principle extends to specific performance as well. 


\section{The real world in which the sharing bargain is not legally enforceable.}

In a world in which the sharing bargain is not legally enforceable, a contractual relationship between independent practitioners, by definition, is an ineffective means of securing the gains from diversification. Because lawyers would anticipate that a mere contractual sharing agreement would be unenforceable, no one would enter into such an agreement. ${ }^{42}$ Greater promise of enforceability would be necessary to induce lawyers to enter into sharing bargains. The law firm provides such promise. Thus, it is hardly surprising that firms are the dominant organizational form through which diversification is sought. The interesting questions become: How has firm organization developed to discourage ex post opportunism and how successful has this proven to be?

Although understanding how law firm organization responds to the need to constrain cheating on the sharing bargain will occupy our attention in much of the remainder of the article, at this point it would be helpful to describe in greater detail the two principal forms of opportunism, what we style grabbing and leaving. As we have described it, the ex ante sharing bargain is an agreement among lawyers to allocate firm income on a basis other than their respective marginal products, entered into at a time before these marginal products are known. Opportunistic behavior occurs when the lawyers later discover their actual marginal products. The more productive lawyer might then respond in one of two ways. He could either demand more than his due under the original sharing bargain-grabbing-or he could withdraw his services from the firm and, no longer subject to the sharing bargain, earn a return on his human capital commensurate with his actual marginal product-leaving. The two responses, of course, are closely related; it is the threat of leaving that allows grabbing to be successful. ${ }^{43}$ And both should ring

42. This prediction is consistent with the fact that we have never encountered, either personally or in the literature, this form of sharing bargain.

43. One puzzle is why lawyers ever actually have to leave. The new firm is presumably prepared to pay the departing lawyer his real marginal product. But why is not the old firm prepared to match the bid? Existing theoretical literature suggests that the party with the best information should be the highest bidder in an auction. See, e.g., Milgrom \& Weber, $A$ Theory of Auctions and Competitive Bidding, 50 Econometrica 1089 (1982). One would suppose that the new firm must know that the original firm has better information concerning the actual marginal product of the lawyer who is leaving. 
true. Few practitioners will have missed the experience of listening to a partner complain that less deserving lawyers receive as much as he, and few followers of the current turbulence in law firms chronicled in trade newspapers are surprised any longer when headlines-“"Energy Drain: Morgan, Lewis sees Bulk of Department Leave"44_announce that an individual or group of partners has left an established law firm. But in either event, when the sharing bargain is legally unenforceable, as it is in the real world, grabbing or leaving by the winner will be anticipated. Such behavior will prevent the capture of gains from diversification in the absence of organizational forms that provide self-enforcement of the sharing bargain. ${ }^{45}$

\section{The Importance of Income Division: Alternative Methods of Dividing the Partnership Pie}

Analysis of both portfolio and agency theory directs attention to precisely the same subject: the manner in which firm income is divided. Diversification, the core recommendation of portfolio theory, is achievable only by means of an agreement specifying how future income will be shared. Agency theory, in turn, highlights the likelihood that those lawyers who turn out to be more successful than their peers will threaten to leave the firm unless they receive their real value-a demand for a quite different manner of dividing firm income. Thus, it is possible to determine whether a law firm has successfully created an institutional structure that constrains opportunism by examining its method of dividing firm income. Firms that have devised effective constraints will have formulas unrelated to partners' marginal products; firms that have not devised effective constraints will have been

Thus, any time the new firm is successful in hiring the winner, there is an implication that a party with better information concerning the lawyer's real value would not bid that high. The interesting question then is why, given the original firm's better information, all ex post opportunism on the part of the winning lawyer does not take the form of grabbing.

44. Legal Times, Dec. 12, 1983, at 1, col. 2.

45. Observers have paid increasing attention to the concept of self-enforcing contracts-contracts which are performed because of the incentives created by the transactional setting, rather than by the threat of legal enforcement. See, e.g., Klein \& Leffler, The Role of Market Forces in Assuring Contractual Performance, 89 J. PoL. EcoN. 615, 615-16 (1981); Telser, A Theory of Self-Enforcing Agreements, $53 \mathrm{~J}$. Bus. 27 (1980); Williamson, Credible Commitments, supra note 31 , at 519. Because the ex ante sharing agreement is legally unenforceable, this form of self-enforcement is the only relevant kind. 
pushed by grabbing or leaving toward a formula that divides income by measuring marginal productivity.

The importance of the manner in which a firm divides its income, however, goes beyond merely identifying whether or not the firm has successfully captured the gains from diversification. Increasingly, the method of pie-division, because of the performance incentives it creates, is seen as an independent determinant of law firm productivity and success. There is a growing consensus among consultants and academics that sharing-oriented systems are the worst, and that a partner's share should depend primarily upon his productivity. These experts claim that the traditional methods deaden incentives ${ }^{46}$ and are detrimental to the firm's long-run potential for prosperity and survival. ${ }^{47}$ One effect of this emphasis on marginal productivity is the limiting of the gains available from diversification. ${ }^{48}$ A second effect, however, should be the reduction of partnership instability. By institutionalizing "grabbing"- the demand by a partner that he be paid based on marginal product-the experts' approach to pie-division should curtail "leaving." Yet, anecdotal evidence suggests that instability seems to be increasing.

46. See Heintz, Elements of Law Firm Competition, NAT'L L.J., Dec. 26, 1983, at 15, col. 1,19 , col. 2. For examples of articles that either assume or stress this need for productivity-based compensation, see Basile \& Sandbach, Practical Aspects to Implementing the Profit Center Concept of Income Distribution, 7 Legal Econ., May-June 1981, at 37 (suggesting an income distribution scheme designed to reward a partner for his role as a developer of work, as a supervisor of associates, and as a worker); Cantor, Dividing Firm Income in the 1980's, 23 LAW OFfice ECoN. \& MGMT. 191 (1982) (outlining several different approaches to partner income distribution); Heintz, New Trends in Partner Profit Distribution, 55 Wisc. Bar Bull., Oct. 1982, at 24, 26 (proposing a number of "performance criteria" for determining partner compensation using such bases as quality of legal work, new business originated, client responsibility, billable hours, fee adjustment, collection performance, ability to supervise and train, management and administration, and performance in outside activities); Reed, Income Determination $E$ Distribution, 5 LEGAL Econ., Nov.-Dec. 1979, at 12 (discussing several systems for distributing firm income on the basis of productivity).

Several papers delivered at an October 1983 conference sponsored by The American Lawyer, and entitled "Allocating Partner Shares, Assuring Partner Productivity, and Other Issues of Intra-Partnership Governance in Today's New Legal Marketplace" also assumed income division strategies must necessarily take productivity into account. See, e.g., Heintz, Allocating Partner Shares; Maister, Professional Service Firm Management; Weil, What To Do About Unproductive Partners.

47. Moldenhauer, supra note 6 , at 27.

48. One could characterize the emphasis on marginal productivity as a response to the incentive to shirk in a firm committed to capturing the gains from diversification. Sacrificing these gains entirely by moving to a marginal product system seems to be a rather extreme solution to the shirking problem, however. 
The puzzle becomes more complicated upon examination of the experts' claim that a seniority system is inconsistent with firm success. Several of the most successful large firms, including Cravath, Swaine \& Moore, ${ }^{49}$ Covington \& Burling, ${ }^{50}$ and Wilmer, Cutler \& Pickering, ${ }^{51}$ remain committed to essentially "lockstep," seniority-based compensation systems and yet seem to be more profitable than ever. These examples pose the problem directly: Why are some prosperous and stable large firms able to divide the pie according to a sharing bargain that appears to be at odds with the self-interest of the most productive partners? What curtails grabbing or leaving?

Unraveling these puzzles, and understanding the implications of the answers for law firm organization, will occupy our attention for the remainder of the article. We begin in this part by examining two polar methods of pie-division: a seniority-based sharing model, which can be best understood in terms of our diversification analysis; and a marginal product approach, which in the extreme case involves no diversification of human capital at all. This examination provides a catalogue of the interrelated advantages and disadvantages of both methods, and structures our consideration in Part III of how successful sharing firms constrain grabbing and leaving.

\section{A. The Sharing Model: Achieving Diversification or "A Mutual Fund for the Benefit of the Retired and Disabled"?}

Many established corporate law firms traditionally have divided profits on the basis of a seniority system. Under such a system, lawyers are typically grouped into classes based on their year of admission to the partnership and their income will depend upon the seniority of their class. For our purposes, the pure case would have the following elements:

(1) each partner's share of profits depends entirely upon his

49. See, e.g., Brill, What Recession? Why Cravath's Balance Sheet Looks as Good as Ever, AM. LAw., Mar. 1983, at 1, col. 1 (Cravath, Swaine \& Moore) [hereinafter cited as Brill, What Recession?].

50. Although Covington \& Burling's method of dividing income is not entirely based on a lockstep seniority system, it is a fair approximation since "[p]artnership shares are generally distributed evenly among those of the same general age." Marcus, Covington Challenge: To Stay on Top, Nat'l L.J., May 4, 1981, at 30, col. 3.

51. Wilmer, Cutler \& Pickering, Description of the Firm (1984-85), at 12 (on file with the Stanford Law Review). 
seniority, which is itself determined on the basis of the class to which he has been assigned;

(2) a partner's class depends only upon the year he was admitted to the partnership and cannot be changed;

(3) all partners in a single class earn the same income;

(4) in any given year, the relationship between the incomes of partners in different classes is based upon a fixed, predetermined ratio; and

(5) the members of each class march "lockstep" down the compensation path until after a fixed number of years they all become "full share" partners. ${ }^{52}$

This model is best understood as a means of capturing the gains available from diversification. Under a lockstep seniority system, an individual lawyer, upon being admitted to the partnership, is quite literally exchanging his human capital for participation in a portfolio of human capital diversified both with respect to the personal characteristics of the lawyers and with respect to specialty. Indeed, it is striking just how well diversified the portfolios of established firms are. New partners in such firms in essence "buy into" mutual funds through which they are able to share not only in the future income of their contemporaries, but also in the future income of lawyers who offer differing levels of expertise and experience and who span two or even three generations. In other words, "buying into" a lockstep traditional firm

52. Obviously some partnerships that allocate income largely on the basis of seniority may nonetheless lack several of these elements. However, this model is not simply a theoretical abstraction. Steven Brill recently found all five elements to be present in Cravath, Swaine \& Moore's system, for example:

No partner or committee has anything to do with partnership compensation; that is totally based on seniority, with all partners reaching their maximum draws when they have been members of the firm for 16 years. Thus, in 1983, 21 partners are at the top end of the 3:1 senior/junior partner earnings spread. . . "What we have is a firm that has all the advantages of tenured professorships," says Boies [a Cravath partner]. "All partners can do whatever they want," Boies adds. "No one controls them."

Brill, supra note 49 , at 49 , col. 2.

The following anecdote perhaps best reflects Cravath's commitment to lockstep seniority:

Some years ago, mourners at the funeral of a Cravath, Swaine \& Moore senior partner were treated to a singular spectacle.

Thirty five Cravath Swaine partners, all honorary pallbearers, marched down the aisle for their fallen comrade in a solemn procession, two-by-two, in precisely the order their names appeared on the firm's letterhead.

Margolick, Wall Street's True Blue Chip, Nat'l L.J., Jan. 14, 1980, at 1, col. 1. 
offers a more diversified portfolio than that available in a partnership made up of lawyers in a single age cohort.

This sharing model depends upon neither the existence of any particular ratio between the income of the most senior partners and that of partners in the most junior class, nor the number of steps to "parity," although these issues are often the focus of debate in the real world. Its essential characteristic is that partners in each class be treated as equals-that they march together lockstep down a road at the end of which they will eventually receive a full share. In theory, the ratio between the income of the most senior partners and that of the least senior partners, and, within reason, the length of the road to a full share, are not central, so long as the terms of the bargain are known in advance and not subject to change. Indeed, assuming that all partners have the same expectations concerning future firm income, any number of different ratios and rates of progression would provide an entering partner with the same expected present value of lifetime earnings within the firm. ${ }^{53}$

As a matter of theory, a partner's cash flow need not be affected by his firm's choice of ratio and length of time to full share. So long as the firm's future income is known and every lawyer is effectively bound to work for the partnership until he dies or retires, the present value of a partnership interest can be known upon entry. The timing of actual cash flows would be largely a matter of indifference because the existence of markets for borrowing and lending would allow each partner to alter whatever cash flow the firm imposed to suit his own tastes.

In the real world, however, the ratio matters a great deal. A high ratio and a long road to parity mean that the partnership payoff is heavily weighted towards a lawyer's later years. An entering lawyer faces the risk that the firm may suffer a decline or even break up before he or she reaches the top. And this only

53. The graph on the following page illustrates this point by plotting three income streams with identical present values. One partnership has a 3:1 ratio, with the newest partner starting at $\$ 90,000$ per year and the top partner earning $\$ 270,000$ per year. This firm has 12 steps to the full share. The second firm has a 5:1 ratio, with 20 steps. The newest partner earns about $\$ 67,000$ and the most senior earns just shy of $\$ 340,000$. The third scheme involves eight steps of $\$ 12,500$ each, with the newest partner earning nearly $\$ 140,000$, and the most senior earning almost $\$ 240,000$. Using a $4 \%$ discount rate, which is not inappropriate for flows net of inflation, the net present value of the expected income until age 65 is identical under each of the three lockstep systems, notwithstanding the very different ratios and rates of progression. 
exacerbates a highly productive lawyer's incentives to grab or leave: A young partner may believe he is worth more now; having to wait increases the risk, and therefore decreases the value, of his interest in the partnership. At the other extreme, were a firm to pay its lawyers almost all of their expected lifetime incomes in the early years, there would be an enormous incentive either to shirk ${ }^{54}$ or to leave (depending upon each lawyer's pref-

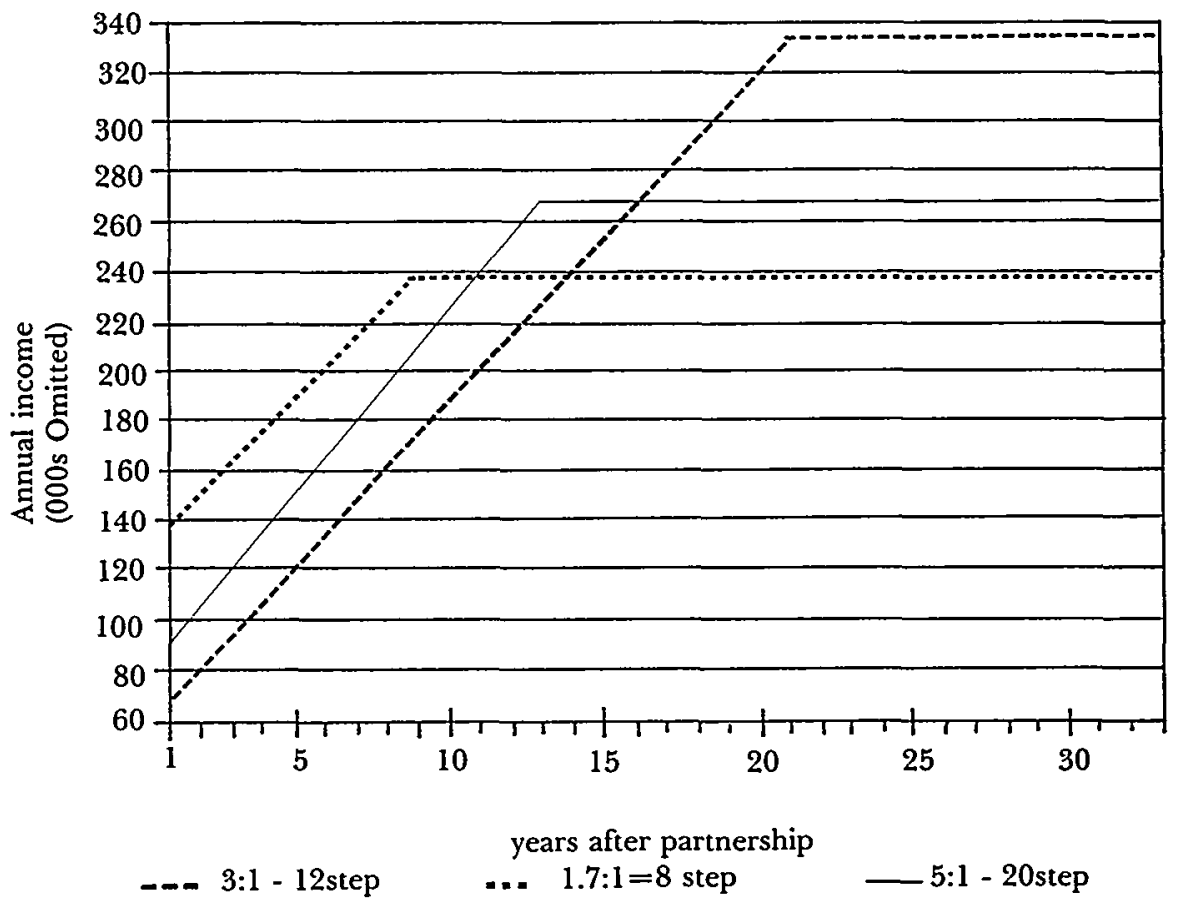

Hypothetical example of three life cycle earnings streams with equal present value upon admission to partnership.

54. The shirking problem has been the focus of most of the criticism of the sharing model during the last ten years. See Moldenhauer, supra note 6, at 27.

Shirking, of course, is not a new phenomenon. What has changed is the competitive environment in which law firms now operate and the nature of institutional responses that are commonly perceived as effective means of responding to the threats presented by this environment:

Ten, even five years ago, running a law practice as a profitable business enterprise merely meant doing more of what you had already been doing well. But the world is different now. Profit margins have fallen dramatically; law partners' incomes have not kept up with inflation. Forces are at work-economic, social and technological forces-that require partners of law firms to focus on management and think about how to do things differently . . . .

Because there is less money to go around, partners are interested in more 
erence between leisure and the income he could earn by joining another firm) after receiving the bulk of his expected future earnings from this firm. Nonetheless, a lockstep seniority system, which implements a progression that minimizes these problems, can provide individual lawyers with the opportunity to capture the gains from diversifying their human capital.

As we stressed in Part I, a sharing model designed to capture the gains from diversification will, if successful, create its own problems-shirking, grabbing, and leaving. Louis Auchincloss, himself a Wall Street lawyer, provides a wonderful literary rendition of these problems in his novel The Partners. ${ }^{55}$ A younger partner, Dan Purdy, had been selected for the management committee of his firm, which allocated income on the basis of seniority. Over lunch following his selection, Purdy urgently suggested to Beeky Ehninger, an aristocratic and friendly senior partner, that there were "inequities that shouldn't go unredressed another day."

"Inequities? What inequities are so pressing?" Ehninger asked. Purdy's response focussed on the firm's method of pie division:

"The partners' percentages, to begin with. Do you think it is equitable that Hal Gavin should receive a larger share of the firm profits than I? Or Burrill Hume? Or Alex West? An accountant friend of mine described our partnership agreement as a mutual fund for the benefit of the retired and disabled."56

Purdy soon thereafter circulated a memorandum proposing that the firm's system be changed to one "whereby credit for every dollar of the firm's gross income be attributed to the partic-

refined approaches to distribute profits among themselves-approaches that differentiate the major producers from the lesser producers in a more pronounced fashion. What constitutes contribution is also being reconsidered; focus is on behavior that relates closely to profit production, including contribution as a manager in the business. As many of the old, authoritarian managing partners retire, the next generation wants to bring income distribution methods into the light and adopt more democratic and quantitative methods. We see a heightened interest among partners in the details of the firms' income distribution systems, including consideration of incorporating defined measurement criteria, increased information about individual performance, formal approaches to the calculations, and more formal administrative approaches in general.

Heintz, The Economic Future of Law Firms: 1984 and Beyond, 67 A.B.A. J. 446, 447 (1981).

55. L. Auchincloss, The Partners (1974).

56. Id. at 11 . 
ular partner or partners deemed responsible for earning it." 57 Not surprisingly, the senior partners refused. Within a month, Purdy resigned from the firm, taking several important clients and two associates with him.

The challenge of the sharing model is thus to provide diversification without giving rise to shirking, grabbing, or leaving.

\section{B. The Marginal Product Approach: The Problems of Measuring Productivity}

In order to give lawyers an incentive to be productive-i.e., to avoid the risk of shirking posed by seniority systems-the new conventional wisdom is that a firm should divide the pie on the basis of productivity, rather than seniority. Each year firms should attempt to determine each partner's relative contribution to firm productivity and then divide income in accordance with this determination. As an abstract proposition, paying each partner in proportion to his contribution to firm profitability sounds straightforward enough, albeit coming at the expense of diversification. In actual operation, however, it is a very complicated task that is impossible to accomplish with complete accuracy. Not only is there likely to be a gap between actual productivity and the firm's approximation of productivity, but the use of some formula to make this approximation also leaves the firm vulnerable to a new set of agency problems: Partners are given an incentive to maximize their own income by maximizing the factors measured by the formula, rather than by actually maximizing their productivity.

To expose these complications, we begin with the simplest case where the firm is not really a partnership at all, but instead is simply a vehicle to share expenses.

\section{A pure expense sharing model.}

Suppose Mr. Sullivan and Ms. Cromwell rent offices together, hire a secretary together, hire an associate together, and share the costs of a common library, but each lawyer remains responsible for his or her work and billing, and receives only his or her own gross receipts. In short, only expenses are shared. Most of these expenses would be rather easy to allocate. Secretarial time and associate time could be allocated on the basis of work done,

57. Id. at 17 . 
although allocation of the library expense might be a bit more arbitrary. But in all events, the important thing to recognize about this arrangement is that each lawyer, in effect, remains a solo practitioner, albeit one who is trying to achieve some economies of scale. The system perfectly measures each lawyer's marginal product because there is no team production of income. Indeed, the system's very accuracy results from the fact that in allocating shared costs the attorneys can rely upon cost accounting techniques that are by now quite sophisticated. In contrast, the available techniques for allocating revenues among profit centers-for example, as between the lawyer who attracted a client and the lawyer who did the work for that client-are much less developed. ${ }^{58}$ The absence of income sharing, however, does mean that the arrangement involves no element of diversification of human capital.

\section{Measuring productivity by hours worked.}

Moving up a step in complexity, the partners could treat all revenues as belonging to the firm and divide profits in the same proportion as the product of the number of hours each lawyer worked times his or her hourly fee bears to the firm's total revenue. Analyzing this intermediate step is particularly useful because, depending on the choices made in developing the formula, it can yield several quite different results and thus can be used to illustrate a number of important points.

The first variable that affects the result is the method of determining each lawyer's hourly fee. Suppose, for example, that the lawyers determine to follow the traditional approach and set fees based on number of years of experience, with a ceiling above which all lawyers charge the same fee. It should be apparent that the effect of this approach is to reintroduce important aspects of the sharing model. So long as all lawyers work the same number of hours, the result is identical to a sharing model, with the number of steps to parity equal to the number of years needed to attain the highest billing rate. Indeed, we might well describe

58. This problem has received more attention in the context of determining whether separate accounting adequately measures the income of a multistate business for state income tax purposes. Because of the difficulty of allocating revenue, as opposed to costs, sophisticated analysts view shared revenue sources as of special importance in deciding whether formula apportionment is necessary. See C. McLure, Jr., Defining a Unitary Business: An Economist's View (available at Hoover Institution, Stanford University Working Papers in Economics No. E-83-5, 1983). 
such an approach as a sharing model with an hours component to serve as a check on shirking.

This correspondence between a method of pie-division intended to be based on marginal productivity and one seemingly premised on sharing principles suggests an important relationship. The coarseness of the productivity measurement directly determines the degree of sharing that may remain, notwithstanding the productivity formula. In essence, individual lawyers diversify their human capital with respect to all factors bearing on productivity that the marginal product formula does not take into account. The problem, however, is that the coarseness of the productivity measure is also directly related to the degree of perversity of incentives that the approach creates. Anything less than complete sharing results in the marginal product approach's equivalent of shirking-strategic behavior intended to emphasize only the productivity factors taken into account in the formula, at the expense of all others. Thus, while there may be sharing with respect to those factors left out of the formula, it also creates incentives for lawyers to invest as little time as possible in those factors and thus to minimize the actual sharing that takes place.

The consequences of this relationship are greater than the mere alteration of the relative distribution of the pie. Just as shirking may result in a reduction in overall output in a pure sharing model, so too may the incentives resulting from the coarseness of the productivity formula reduce the size, as well as alter the distribution, of the pie in a marginal product approach. An examination of two important factors that the hypothetical productivity formula outlined above does not take into accountefforts at attracting clients and time spent on firm managementillustrates this point.

Consider first the matter of attracting clients, hardly an unimportant determinant of firm success. Although the simple "hours worked" productivity formula does not explicitly credit this factor, it does create some positive incentive to attract new business. In order to have a project on which to work, a lawyer must have clients. Thus, a system which on the surface rewards only hours worked necessarily encourages some effort at attracting clients. The incentive, however, is at best incomplete. A lawyer gets no reward for attracting more clients than he or she can service alone. Moreover, because our hypothetical productivity formula measures only hours worked, it provides attorneys with incen- 
tives to perform all of the legal work for their individual clients as opposed to seeking the assistance of other lawyers who may be better equipped to service these clients with respect to a particular matter.

A similar problem arises with respect to firm management. Our simple "hours worked" productivity formula gives no credit at all for this activity despite its obvious importance. Yet how one would alter the formula to incorporate firm service is not entirely clear. For example, much firm administration, while perhaps less exciting than trial or transactional work, may also be less demanding and certainly is less intrusive on one's personal life. Should complete credit be given for hours spent on administration or only partial credit?

A simple approach based only on hours billed illustrates another general point about the use of productivity formulas generally: However coarse or fine, formulas are, at best, imperfect proxies for the characteristic that is actually at issue but is, in fact, unobservable-actual productivity. Our simple formula measures only effort, not results. For example, different lawyers work at different speeds and with different skill. An hour spent by one lawyer may be less productive than an hour spent by another. It would hardly be unreasonable for the more efficient lawyer to object to a system that, in effect, imposes a penalty for efficiency. The result is that the coarseness of the productivity formula determines not only the extent to which sharing is reintroduced and the extent to which perverse incentives are created, but also determines the extent to which the potential for the same problems which prompted rejection of the sharing model in the first place-shirking, grabbing, and leaving-are recreated in the productivity model.

\section{The difficulty of creating a formula: the example of client generation.}

It may seem as if there is an easy response to the previous section's observations: Devise a carefully crafted formula that is sufficiently refined to avoid the problems that we have identified. An examination of the difficulties that arise in determining how, and to what extent, to reward something as seemingly straightforward as client generation demonstrates, however, that the problems cannot easily be made to disappear.

The idea behind a system that rewards client generation inde- 
pendently of the number of hours that a lawyer works is straightforward. It is to the firm's advantage if a lawyer brings in more business than the lawyer can satisfy himself. Work is thereby created for associate lawyers and the firm earns additional profit by buying the associates' time at "wholesale" and selling it to the client at "retail."59 As practitioners well know, however, client generation is time consuming, difficult, and chancy; but if lawyers are not rewarded for spending their time this way, as is the case with the straight hours worked approach, they will invest too little time in an activity that is quite important to the firm and that, for at least some lawyers, may be a more productive use of their time than lawyering. Thus, so long as we operate on the premise that a lawyer's share of the profits should depend on productivity, it is a small step to conclude that measures of productivity should take client generation into account.

The more difficult questions are how much weight a formula should accord client generation and what the formula itself should look like. Moreover, once again we confront the problem that any formula will always create incentives to maximize the factors that it weighs, to the detriment of the goal whose attainment is its purpose. For example, suppose we decide to reward client generation with a one-time bonus when the client first employs the firm. This creates an incentive to attract the client in the first place, but creates no incentive for the lawyer who initially attracts the client to assure that the client remains satisfied and therefore willing to provide the firm with additional work in the future. ${ }^{60}$ Firms can mitigate this problem by giving the lawyer who generates business a continued bonus determined by the volume of work that the client provides in any period. This refinement, however, hardly solves the general problem. If a significant part of the lawyer's earning depends on the amount of work generated by particular clients, an incentive is created for the lawyer to resist efforts by others to get to know the client

59. Work is also created for partners who have been less successful at finding clients to fill up their time. Note, however, that there are questions about the relative compensation of the partner bringing in the client as opposed to the partner actually doing the work. See note 60 infra and accompanying text.

60. This problem might be alleviated somewhat if the lawyer's ability to take the client with him upon leaving the firm increases his value in the market for lawyers. However, this is less of a solution to the problem of perverse incentives than it is a recognition that a marginal product approach cannot entirely eliminate the twin problems of grabbing and leaving. 
because his livelihood is put at the risk of performance of others. ${ }^{61}$ Moreover, one would also want to control not only for attracting the work, by also for its profitability. If the lawyer's client-generation bonus depends only on the number of hours that he works for the client, an incentive is created to bill the client at a lower rate in order to encourage a greater amount of work, notwithstanding the fact that the firm's overall profit might be reduced as a result: One partner may well be better off with a larger piece of a smaller pie. A formula thus does not prevent the interests of the individual lawyer and those of the firm from diverging.

Finally, a formula that rewards client generation may also create incentives to grab or leave. It would hardly be surprising were a client's loyalty to shift from its original contact to the lawyer who actually does its work. If the formula does not reflect this shift in role, it does not reflect the productivity of the client's

61. A recent article about the split up of the Washington, D.C. firm of Leva, Hawes emphasizes this problem. This firm had a rigid formula that accounted for overhead costs, billable hours, and business development, but split apart because of the formula.

[M1]any Leva, Hawes partners became upset that the allocation of partnership revenues encouraged the "Balkanization" of Leva, Hawes' practice. Avoiding a problem that divides some firms, Leva, Hawes did give credit for business development. But these partners believed that rainmaking was credited so much and with such rigidity that partners' individual interests were put ahead of the firm's overall interests. The system "allowed certain partners to establish their own fiefdoms without any regard to the firm as a whole," says a former partner.

The compensation was based on a rigid formula that took into account the firm's overhead costs, the partner's billable hours, and the lawyer's business responsibility. Two-thirds of the partner's compensation would come from billable work hours and another third would come from business development.

The key was the business development part of the equation. If a partner brought in a client and worked on that client's business himself or doled out part of the activity only to associates, he could keep the entire profit for himself. "The incentive was never to give up any client work to another partner," says a lawyer who worked at Leva, Hawes. At the same time, the attorney adds, once a partner brought a client to the firm, he always received a portion of the business development profit regardless of whether he did any work at all on a specific case.

Because partnership earnings had no cap, in a flush year an individual could make a fortune and not share it with another partner whose litigation had ended. Thus incredible differentials existed both between partners and between the amounts a lawyer might earn from year to year. (Partners had a minimum draw that was set at only approximately $\$ 40,000$ per year, according to sources).

Moore, Shrunken Leva, Hawes Reels As Lawyers Who Left It Thrive, Legal Times, Jan. 30, 1984, at 1, col. 2. 
current lawyer. That lawyer is then in the same position as a more productive lawyer in a sharing firm-his income does not reflect his actual productivity-and he has the same incentives to grab and leave. ${ }^{62}$

\section{Summary}

Our examination of the two paradigmatic methods of dividing the pie demonstrates that, in the absence of agency costs, a sharing model has the advantage of capturing the gains from diversification. Once agency costs are introduced, however, there is, in the abstract, no easy basis on which to prefer one model to the other. A sharing model captures the gains from diversification and avoids the divergence between profit maximization for the firm and profit maximization for the individual partner that accompanies, to a greater or lesser extent, any productivity formula. A sharing model, however, creates a greater incentive to shirk, grab, or leave than does a marginal product approach. A marginal product approach, in contrast, will reduce shirking, but eliminate diversification. And to complete the terms of the necessary balancing, a marginal product approach creates its own set of perverse incentives and may also be subject to the shirking, grabbing, and leaving problems that are generally associated with the sharing model.

The choice between a sharing model and a marginal product

62. Consider the following excerpt from an account of the disintegration of Watson, Leavenworth, Kelton \& Taggart, a New York firm that specialized in patent and trademark matters:

As an incentive to attract new business, Watson Leavenworth gave a portion of all profit from each case to the lawyer who brought in the case. . . . However well intentioned the method, it ultimately became a great source of friction between those who got the clients and those who did the work . . . .

The "client-share" system encouraged Watson Leavenworth lawyers to guard their client affiliations against intrusion by others, creating an atmosphere of competition among partners. Some partners suspected others of "hoarding" cases.... .

A typical dispute arose several years ago when Elmer Helferich, a contemporary of Mr. Watson, retired to an of counsel position. Mr. Helferich had had the client share for Philip Morris, which provided him a sizable income.

Howard Kothe, a partner who had been doing much of the Philip Morris work, demanded that the company's client share pass to him; the other partners wanted the client share to be distributed evenly, making Philip Morris a "firm client." Implicit in the dispute was that Mr. Kothe might leave and take Philip Morris with him. Eventually, after a good deal of divisive debate, a compromise was reached.

Weingarten, Breaking Up, Nat'l L.J., June 1, 1981, at 26-27. 
approach thus turns on the ability of a law firm to devise a structure that most effectively reduces the agency costs associated with cooperation. If the agency problems associated with a sharing model cannot be overcome, a marginal product approach, rather than an ineffective sharing model, becomes the second best alternative. The observable success and stability of some firms suggest, however, that the first best alternative-a sharing model with reduced agency problems-can sometimes be achieved. The next two parts consider elements of law firm organization as responses to the three agency problems of a sharing model. Part III focuses on the organizational constraints that appear to limit grabbing and leaving. It also emphasizes the potential of a sharing model that has solved these problems not only to capture the gains from diversification, but also to be more productive than a marginal product approach. Part IV, in turn, focuses on the organizational response to the remaining agency problem associated with the sharing model-shirking.

\section{Individual Capital Versus Firm-Specific Capital: Constraints ON GRabBing aND LEAVING IN}

\section{a Sharing Model}

Our discussion thus far has led to the conclusion that the character of the agency costs that law firms confront-shirking, grabbing, and leaving-is an important determinant of law firm internal organization. Organizational responses to agency problems are particularly important because if shirking, grabbing, and leaving can be constrained, a sharing model becomes preferable to a productivity approach. ${ }^{63}$ In this part, we consider potential constraints on grabbing and leaving in a sharing model

63. The agency problems associated with implementing a sharing model are also of particular interest because they have received comparatively little attention. For example, in considering the organizational structure of professional partnerships, Fama and Jensen simply assert, without examining alternative approaches and without considering the cost in terms of foregone diversification, that a marginal product approach is essential to constrain shirking:

The residual claims of large partnerships take a direct approach to this agency

problem. The residual claim is not generally a fixed share of net cash flows.

Rather, a partner's share is renegotiated annually on the basis of past perform-

ance and estimates of likely contributions to future net cash flows.

Fama \& Jensen, Agency Problems, supra note 30, at 335. It is hard to treat this statement as an empirical claim because no underlying data are disclosed. As a historical matter, we believe the assertion to be substantially inaccurate, and even today, as our discussion indicates, to be a seriously incomplete description of how many large and successful partnerships divide profits. If their assertion is a normative claim as to how large part- 
and develop what we believe to be the most significant constraint: the concept of firm-specific, as opposed to individual, capital. We then examine the important sources of firm-specific capital, and conclude-notwithstanding the clear consensus among commentators and consultants concerning the superiority of a marginal product approach ${ }^{64}$-that a sharing firm has the potential to create firm-specific capital more effectively than does a firm pursuing a marginal product approach.

\section{A. The Distinction Between Individual Capital and Firm-Specific Capital}

As we stressed earlier, every lawyer in a firm has made an investment in his or her individual human capital. For the purposes of this analysis, we can measure the value of this investment as the capitalized value of the amount of money that the lawyer would expect to earn by leaving the firm and taking alternative employment-either by joining a different law firm or by forming a new law firm. ${ }^{65}$ By way of contrast, the value of firm-specific capital is the capitalized value of the difference between a firm's earnings as an ongoing institution and the combined value of the human capital of its individual partners, if this human capital were deployed outside the firm in its next most productive use. Because firm-specific capital can be neither easily removed from the firm nor duplicated outside the firm, the return on this capital is available to lawyers within the firm but is lost to lawyers who leave the firm. ${ }^{66}$ Examples of this phenome-

nerships should divide profits, for reasons we discuss at length, it remains seriously incomplete.

The agency problems and organizational responses associated with a marginal product approach have received more attention because incentive compensation schemes and profit center accounting techniques are common to many businesses, while the sharing model seems to be peculiar to professional service organizations.

64. See note 46 supra.

65. For ease of presentation, we make the simplifying assumption that all other legal and nonlegal alternatives offer lower returns.

66. In developing our concept of firm-specific capital, we found recent work by our Stanford colleagues Jeremy Bulow and Myron Scholes concerning the "ownership" of pension assets to be quite useful. See Bulow \& Scholes, Who Owns Assets in a Defined Benefit Pension Plan, in Financial Aspects of the U.S. Pension System (Z. Bodie \& J. Shoven eds. 1984) [hereinafter cited as Pension System]; Bulow, Scholes \& Menell, Economic Implications of ERISA, in PENSION SySTEM, id.

Our analysis is analogous to the idea, originally developed as an explanation for vertical integration, see Klein, Crawford \& Alchian, Vertical Integration, Appropriable Rents, and the Competitive Contracting Process, 21 J. L. \& ECON. 297 (1978); Williamson, The Vertical Integration of Production: Market Failure Considerations, 83 AM. Econ. Rev. PaPERS \& Proc. 
non readily come to mind. Having IBM as a client is valuable to Cravath, Swaine \& Moore, but if there is no individual partner who upon leaving the firm, can take IBM with him, then the client relationship with IBM is an asset of the firm. ${ }^{67}$ Returns on this asset are available to individual lawyers only so long as they remain within the firm.

Our basic thesis is that firm specific capital, by constraining grabbing and leaving, provides the glue that holds together an organization committed to the sharing model. Without firm capital, the ex ante sharing bargain is subject to ex post cheating: More productive partners may claim, after the fact, a larger share than they are entitled to under the original sharing bargain. The strength of their claim, however, depends not on the accuracy of their belief about their relative productivity within the firm, but on whether they can earn a greater return on their individual capital in its next best deployment if they leave the firm. Without a realistic threat of leaving for more money, an attempt to grab is likely to be ineffective. In this regard, the Cravath firm again provides a very instructive example. According to a recent article, the full-share partners in Cravath each earned $\$ 855,000$ in 1983 , while the youngest partners enjoyed annual earnings of $\$ 285,000$-a three-to-one ratio. While firms all around it split up, merge, or oust partners, Cravath continues to employ a piedivision system that approximates our pure sharing model, does

$112,116(1971)$, that an investment by one contracting party in assets that are specific to the contractual relationship-that is, assets that have a lower value in alternative usesallows the other contracting party to capture the difference in value by threatening nonperformance. In our analysis the value of this form of "firm-specific" capital is not reduced as a result of nonperformance by an individual lawyer because it is created by the relationship between the law firm as a whole and third parties.

67. Covington \& Burling, another prestigious sharing firm, also seems to possess firm-specific capital in ample amounts:

Now in its $63 \mathrm{~d}$ year, Covington indeed retains the reputation of being not just the biggest but also the best firm in town. Peculiarly, that reputation is an institutional one: Covington \& Burling seems greater than the sum of its parts. It cannot count among its 212 attorneys a single "rainmaker," or a superstar lawyer with an instantly recognizable name, in the mold of Clark Clifford, Lloyd Cutler or Edward Bennett Williams. "Covington gets business because of its trademark, not because somebody played tiddledywinks with Daniel Gribbon when they were in prep school," says one former Covington associate, referring to the chairman of the firm's five-member management committee . . . .

When the time comes to divvy up the profits at Covington, a former partner says, "the firm never lets partners claim they brought in business. The firm did, with its reputation over the long term."

Marcus, supra note 49 , at 1 , col. 4 , at 28 , col. 1 , at 30 , col. 3 . 
no lateral hiring, has no written partnership agreement, ${ }^{68}$ and apparently suffers no defections. And the explanation for so stable a sharing model seems clear. If the earnings figures are correct, it seems unlikely that very many of the Cravath partners could make more money elsewhere. In other words, there is plenty of firm-specific capital to "glue" the partnership together.

We next consider the principal sources of firm-specific capital, a desirable commodity whether a firm is committed to a sharing approach or a marginal product model. We then examine the comparative efficiencies of both approaches in the creation of firm-specific capital.

\section{B. Sources of Firm-Specific Capital}

For our purposes, the critical aspect of firm-specific capital is that a departing lawyer cannot easily take it with him or duplicate it outside the firm. This observation highlights an important difference between most economies associated with size (which produce what might be called "firm capital") and our more limited notion of firm-specific capital. Consider, for example, the benefits from economies of scale or from minimum scale. ${ }^{69}$ To be sure, both help explain why legal services are more efficiently supplied by firms. Neither seems to us to be a likely source of firm-specific capital, however. Because the benefits from both economies of scale and from minimum scale should be achievable at fairly low levels, ${ }^{70}$ a lawyer leaving a firm should be able to recreate them outside the firm at fairly low cost. Thus, the value of these aspects of firm capital differs little inside and outside of the firm

68. See Brill, What Recession?, supra note 49, at 1, col. 1 .

69. See notes 9-14 supra and accompanying text.

70. There are a number of important exceptions. Some kinds of legal work-hostile corporate takeovers may be the best example-require the full time attention of a large number of lawyers over a relatively short period. Other kinds of work-for example, large scale litigation-require part of the time of a large number of lawyers over a long period, thereby necessitating larger scale to achieve the flexibility necessary for efficient staffing. Additionally, specialty diversification and economies of scale may combine to increase the efficient size of a firm. If a firm must contain a number of specialties to capture the gains from diversification, and if each specialty requires a minimum number of lawyers to exhaust scale economies, the efficient size of the firm becomes the sum of the efficient sizes of each specialty group.

While this suggests that even nonspecific firm capital may be difficult to recreate outside the firm, and that the presence of this capital therefore also constrains leaving, the constraint would extend only to forming a new firm, not to joining an existing firm that had already developed its nonspecific capital. For this reason, our analysis will emphasize firm-specific capital because its impact extends to both forms of leaving. 
and, as a result, really should not constrain an individual lawyer's decision to leave his firm. ${ }^{71}$ What is necessary for our purpose is not merely firm capital-economies achievable at fairly low cost in any firm-but firm-specific capital-economies that are available only in a particular firm.

This focus on assets which have substantial value within the firm, but cannot be easily duplicated outside the firm, suggests that the most important sources of firm-specific capital cluster around two related ideas. The first is that clients, as well as lawyers, are essential to a law firm's success. As a result, the client relationship is central to development of a number of types of firm-specific capital. The second has to do with the difficulty a client may encounter in evaluating the quality of legal services offered by different firms. The need for effective means of quality assurance creates the potential for a variety of types of firmspecific capital.

\section{Clients as sources of firm-specific capital.}

As our earlier reference to the value of IBM to Cravath suggests, the idea that stable clients are important to a law firm is hardly surprising. What may be less obvious, however, is that there are a variety of ways by which established client relationships can increase the value of a law firm. And if this is the case, the inability of individual lawyers to retain or reestablish those relationships outside of the firm may significantly constrain their leaving the firm. Client relationships thus become a firm-specific asset.

The value of a predictable flow of work. It is commonplace that a predictable level of demand generally allows a firm to structure production more efficiently. ${ }^{72}$ Consider, for example, a law firm

71. Some types of firm capital may or may not be specific depending on the focus. For example, economies associated with team procedures and knowledge of the strengths and weaknesses of one's colleagues are firm-specific with respect to any single lawyer, but may be nonspecific with respect to the entire team. Thus, where the issue is the split off of an entire specialty group, as with the tax department at Kaye, Scholer, see Partners' Rift Seen at Kaje, Scholer, N.Y. Times, July 25, 1979, at D15, col. 2; Stewart, From Sweatshops to Country Clubs: Summer Associates Rate Their Firms, AM. LAw., Oct. 1979, at 16, these economies would be nonspecific and, therefore, no constraint to "leaving" at all.

72. See, e.g., A. Chandler, The Visible Hand: The Managerial Revolution in American Business 363-68 (1977); M. Porter, Competitive Strategy 303-05 (1980); F. Scherer, Industrial Market Structure and Economic Performance 89-91 (2d ed. 1980). 
with a particular client, such as a bank, that has a large volume of routine, predictable work. The routine nature of the client's work allows this work to be done by associates. Partners thus not only receive a return on their human capital, but also profit through purchasing associates' human capital at wholesale and selling it to the client at retail. Moreover, the predictability of the work allows the firm efficiently to plan its staffing regardless of the mix of partners and associates who actually do the work. ${ }^{73}$ Excess capacity-more lawyers than work-reduces returns.

This point can be generalized: An established client base facilitates effective staffing in the same way as does the existence of a single predictable client. If the firm has a diversified group of clients, it may be able to predict fairly accurately the aggregate demand for the services of its entire client "portfolio" even though it can hardly predict the likely demand of any single client. In budgeting for the next year, a firm need not worry whether a particular client will have the same level of work as it did in the previous year, so long as the client base as a whole generates a predictable amount of work. ${ }^{74}$

If a firm is able to plan efficiently either because it has one predictable client or because it has a predictable portfolio of unpredictable clients, it should be able to garner increased profit compared to what it would reap in the absence of predictable client relationships. Even in a market with large numbers of competing law firms, the more efficient firm should earn increased profits because of its lower costs. And if a lawyer cannot duplicate these efficiencies outside the firm-if he cannot take the necessary client base with him-an important element of firmspecific capital exists; an important constraint on "leaving" results.

Client-specific information and the value of the relationship in a competitive environment. An established client relationship results in the creation of another important kind of firm-specific capital. For many types of legal work there are significant start-up costs associated with servicing a client's needs. Most obvious is the investment of time that is necessary to learn enough about the client and its business to provide the needed services. Less obvi-

73. This factor suggests a correlation between firms with successful sharing approaches and firms with banks as longstanding clients.

74. One of the authors recalls Justice Harlan making precisely this point with respect to his old firm, Root, Clark. 
ous costs include the cost of developing a relationship of trust and confidence between the law firm and the client at the operating level-between junior partner and associate on the one hand and the client's middle management on the other-as well as the cost of developing procedures within the law firm to coordinate effectively the group of lawyers who will actually do the client's work.

The investment in these start-up costs has important implications for the relationship between the lawyer and the client, even in a competitive environment. A firm's investment in client-specific information after the client has selected the firm and the client's investment in developing a working relationship with the firm results in a material change in the character of the competitive environment that bears on that firm-client relationship. Once this investment has been made, the incumbent firm has a significant cost advantage over potential competitors. To compete effectively with the incumbent-to "steal" its client-another firm would have to incur start-up costs and impose the cost of developing a working relationship on the client. Both of these costs are effectively sunk with respect to both the incumbent firm and the client. The result is that the market for legal services with respect to that client shifts from one characterized by a large number of alternative suppliers to one dominated by a single supplier-the incumbent firm. Indeed, the relationship approaches a bilateral monopoly: Both parties have an incentive to maintain the relationship because termination would be costly for each. The law firm would lose the value of its client-specific investment in information and procedures; the client would be forced to incur both the cost of finding a new law firm and some portion of the same start-up costs originally incurred in connection with the incumbent law firm. ${ }^{75}$

The law firm, of course, benefits from the predictability of the client's demand for its services resulting from the cost-enforced stability of the relationship. Moreover, to the extent that the law firm proves to be better than the client at distributive bargaining, the result should be to allow the firm to keep the lion's share of

75. The insight that competitive conditions shift from large numbers to small numbers as a result of investments in transaction-specific assets originates with Oliver Williamson. See O. Williamson, Markets and Hierarchies, supra note 32, at 26-29. The concept is applied in the context of professional services by DeAngelo, Auditor Size and Audit Quality, 3 J. AccT. \& Econ. 183, 187-90 (1981). 
the benefits of stability. ${ }^{76}$ In either event, the advantages to the law firm of operating as part of a bilateral monopoly, as opposed to operating in a competitive market, together with the inability of a lawyer leaving the firm to duplicate that relationship outside the firm, create an important source of firm-specific capital and, hence, an important constraint on leaving. ${ }^{77}$

\section{The firm as a means of quality assurance.}

The market for legal services is characterized by significant problems of quality uncertainty. From the client's perspective, there are a large number of competing suppliers and it is apparent that the quality of the services rendered differs among suppliers even though the large number of suppliers may keep the price of services equivalent across quality variations. Moreover, it is difficult for a client to determine in advance the quality of services likely to be rendered by a particular law firm. And to make matters even worse, if the client is not very sophisticated concerning legal services, it may have difficulty determining the quality of the services even after they are rendered. ${ }^{78}$

76. Klein, Crawford \& Alchian, supra note 66, develop a theory of vertical integration as a response to precisely this condition. In the context of the market for legal services, the vertical integration response would be for a client to take in-house at least those aspects of its legal needs that require a client-specific investment, perhaps by hiring a general counsel to supervise and coordinate the client's work or, at the extreme, by internalizing some or all of the actual legal work. For a consideration of the impact of increased client sophistication on the potential gains to law firms as the context of the lawyer-client relationship shifts from a competitive market to a bilateral monopoly, see note 120 infra and accompanying text.

77. This is not to say, however, that the constraint is entirely effective. Where the client-specific information and procedures are embodied in a small enough number of lawyers, the asset is not firm specific with respect to them. For that client, the particular group of lawyers is the firm.

78. The most obvious after-the-fact means of evaluating the quality of legal services is to equate the quality of the services rendered with the desirability of the outcome of the matter in connection with which the services were rendered. Evaluation of the quality of the services of litigation counsel, for example, would turn on whether the verdict or settlement is a favorable one. The problem, however, is that the outcome in any single matter is a function not only of the quality of the lawyer, but also of a large number of random elements-elements that are under the control of neither the lawyer nor the client-such as the quality of the client's case, the quality of opposing counsel, the sagacity of the opposing principal, or the wisdom of the judge. As a result, the particular outcome would be a highly imperfect measure of the quality of the lawyer's services. To be sure, if the other elements were truly random, they would cancel out over a series of outcomes, much as does the error term in a regression equation. However, this process takes many repetitions and would be available only to clients whose legal needs permitted use of the same lawyer a sufficient number of times.

For business matters, it is also difficult to tell immediately after the transaction 
A client who is risk averse ${ }^{79}$ thus has a significant incentive to reduce the risk-i.e., the expected variation in the quality of legal services actually obtained-associated with purchasing legal services. The client can accomplish this by acquiring additional information about the quality of services offered by competing firms. ${ }^{80}$ Because services that have less variation in quality are more valuable to the client, a firm that is more effective at assuring a client of the quality of its services is likely to be more successful. The means by which firms assure clients of the quality of their services thus provide another important form of firm-specific capital and another important constraint on "leaving."

The role of quality assurance in client relationships. The difficulty of determining the quality of legal services highlights another potential advantage of an incumbent firm. Should a client decide to change firms, it would have to incur the cost of securing information about the quality of a rival law firm's services, a problem that is exacerbated the greater the client's risk aversion. ${ }^{81}$ The in-

whether the protections insisted upon by the lawyer were necessary. However high the abstract quality of the craft, it is still of low value to the client if it was unnecessary. Indeed, because some events against which protection is appropriate may be of low probability, even their eventual nonoccurrence does not indicate whether the lawyer correctly estimated the probability distribution associated with their occurrence.

79. There is every reason to believe that clients will be risk averse. Even if a corporate client, as an entity, should not exhibit risk aversion in the selection of a lawyer, the individual employee who actually makes the selection probably will be risk averse. If the particular decisionmaker will be blamed for a poor selection, his own self-interest, although not that of the corporation, is maximized by avoiding risk in the selection process. In this sense, a general counsel may have two goals in selecting a law firm: choosing a good firm, and choosing a firm, whether or not actually the best for the matter, whose selection will seem sensible to his superiors even if the legal effort proves unsuccessful.

80. There is a large body of recent literature dealing with consumer and producer behavior in markets in which products are not homogeneous and consumers have imperfect information about the quality of the different products available. See, e.g., Barzel, Measurement Cost and the Organization of Markets, 25 J. L. \& Econ. 27 (1982); Grossman, The Informational Role of Warranties and Private Disclosure About Product Quality, 24 J. L. \& EcoN. 461 (1981). Our treatment here has been particularly influenced by Wiggins \& Lane, Quality Uncerlainly, Search, and Advertising, 73 AM. EcoN. REv. 881 (1983), who stress the importance of risk both in determining consumer behavior and in differentiating between producer efforts to reduce uncertainty by direct or indirect information acquisition.

81. The difficulty caused by risk aversion is that during the period the client is either using a new firm selected on the basis of the firm's general reputation, or trying a new firm in order to develop actual knowledge of the quality of its services, there is a greater risk-an expectation of a higher variation in quality-associated with the new firm's services. This is because both reputation and the initial results of an effort to determine directly the quality of the new firm's services by trying them are only imper- 
cumbent firm may thus enjoy a "cost" advantage that augments any tendency toward bilateral monopoly.

Moreover, precisely because a client that has a long-term relationship with a law firm can be expected to have actual knowledge about the firm's services, the very existence of this relationship may serve as an important source of quality assurance to prospective clients. A potential client may have far better information about the intelligence and judgment of an existing client than about the quality of the law firm's services. If the potential client knows (1) that the existing client has actual knowledge of the quality of the firm's services and (2) that the existing client has good judgment in these matters, then the very existence of the established relationship is an important source of quality assurance to the potential client. ${ }^{82}$ In this way, the presence of existing client relationships can serve as an important "referral" even without the client's active participation. And, as with other advantages of a stable client relationship, ${ }^{83}$ its value as a source of quality assurance is firm-specific. It thus serves as a constraint on "leaving" to the extent that the client's perception of quality is associated with the firm rather than with one or a small number of lawyers.

Strategies for providing quality assurance. In examining strategies by which a law firm can help reduce the uncertainty concerning the quality of its services, it is helpful to distinguish between "searching" and "signaling." Some strategies are intended to facilitate the client's search-its gathering of information that $d i$ rectly reveals the quality of the firm's services. Other strategies are intended to signal indirectly information concerning the quality of the firm's services because of the presumed relationship between the law firm's readily observable behavior, the signal,

fect proxies for the new firm's actual quality. The client already has this information with respect to the incumbent firm. The more risk averse the client, the greater the impact of the differential in information.

82. The value of this signal of a law firm's quality depends on the reputation of the client, not of the law firm. This suggests that the more sophisticated about legal matters the existing client is perceived to be, the more effective this form of quality assurance is likely to be. This relationship between client sophistication and the strength of the signal concerning the law firm's quality takes on some importance when we recognize that the most significant change in the market for legal services is the growth in client sophistication. See note 120 infra and accompanying text. It should be noted, however, that the signal is only one of minimum quality: The floor is set by the existing client's cost of searching for alternative suppliers.

83. See text accompanying note 75 supra. 
and the unobservable quality of the firm's services. In any given case, which strategy will be more effective for a law firm will depend on the client's search costs. The higher the client's cost of acquiring information bearing directly on quality, the more likely it is that the client will place greater reliance on indirect signals of quality, despite the fact that the signaling approach is an imperfect proxy for actual quality. The lower the cost of search, the more likely it is that the client will base its decision on direct information about quality. ${ }^{84}$ While a variety of factors can affect the costs of acquiring direct information about the quality of a firm's services, the most important for our purposes is the sophistication of the client. To determine the quality of a firm's services, the client must know both the type of information to acquire and how to evaluate it. The more sophisticated the client, the more cheaply and accurately it can acquire and evaluate direct information concerning the quality of legal services. From this perspective, a lawyer may be the best person to select a law firm.

This analysis suggests that the methods that firms use to demonstrate the quality of their services should vary substantially depending upon the level of sophistication of the prospective client. Where firms are attempting to attract relatively unsophisticated potential clients, we would expect their quality assurance efforts to take the form of signaling: investments in assets-such as public relations efforts, direct advertising, or fancy officesthat would lose their value were the firm subsequently to render low quality services. The firm signals that it would not be engaging in these activities-putting money at risk-if it did not render high quality services. ${ }^{85}$ Here, of course, the resulting reputation for providing high quality services is by definition a firm-specific asset that cannot be captured by a lawyer or small group of lawyers should they leave the firm. Indeed, to the extent that the signal's power depends on the amount of money put at risk, the

84. Differential search costs coupled with differential levels of risk aversion can result in an equilibrium in which different firms continue to produce products of quite different quality, see generally Wiggins \& Lane, supra note 80 , a result reassuringly consistent with our anecdotal evidence concerning the market for legal services.

85. See, e.g., Klein \& Leffler, supra note 45. The posited relationship between client sophistication and the value of advertising finds confirmation in the fact that the largest volume of advertising by lawyers since its legalization appears to be by lawyers rendering essentially consumer services-divorce, personal injury, personal bankruptcy, or immigration. By way of contrast, firms seeking to serve significant commercial clients do virtually no advertising at all. 
larger the firm, the stronger the signal and the more expensive it becomes to duplicate this signal outside the firm. ${ }^{86}$

The character of a firm's quality assurance activity shifts dramatically when the firm perceives its potential clients to be more sophisticated. Firms can reduce the search costs for sophisticated clients by proffering information that directly demonstrates the high professional quality of their lawyers. ${ }^{87}$ This, it seems to us, helps explain the willingness of major firms to invest the time of their attorneys in writing law review articles and treatises, and in participating in professional panels such as Practising Law Institute seminars. While such activities may at first appear misguided-why give away one's expertise by telling competing lawyers what you know?-in fact these activities provide direct information concerning quality of services to clients sophisticated enough to evaluate it. ${ }^{88}$

This approach to quality assurance has a more indeterminate impact on the formation of firm-specific, as opposed to individual, capital. Writing and lecturing by individual lawyers inevitably builds individual reputations and capital as well as firmspecific capital. Indeed, for a firm this strategy may even backfire. If the result is to so enhance a lawyer's individual reputation that his potential earnings outside the firm become greater than what he earns inside the firm, then "leaving" is encouraged

86. DeAngelo, supra note 75 , at $185-89$.

87. Differentials in a client's search costs may be caused not only by absolute differences in cost, but also by the presence of significant scale economies. The more legal work to be purchased, the lower the per unit cost of information concerning the quality of a firm's services.

88. Differentials in search costs between commercial and consumer clients may also explain the apparent difference in the amounts of scholarly writing undertaken by practicing lawyers with different specialties. For example, we would expect lawyers specializing in mergers and acquisitions or corporate tax to engage in far more scholarly activity than lawyers who specialize in divorce, personal injury, or other forms of "consumer" law. The persons who choose commercial lawyers are often other lawyers who can evaluate the quality of scholarly effort. Casual empiricism supports this prediction. Four out of the five major treatises on mergers and acquisitions are authored by practitioners. Compare E. Aranow, H. Einhorn \& G. Berlstein, Developments in Tender Offers for Corporate Control (1977); A. Fleischer, Tender Offers: Defenses, Responses, and Planning (2d. ed. 1983); J. Freund, ANatomy of a Merger: Strategies and Teghniques for Negotiating Corporate Acquisitions (1980); M. Lipton \& E. Steinberger, Takeovers and Freezeouts (1978) with B. FoX \& E. Fox, Corporate AcQUISITIONS AND MERGERS (1983). Similarly, the number of tax journals in which practitioner writing predominates is substantial. See, e.g., The Journal of Taxation, The Journal of Corporate Taxation, The Tax Law Review, Taxes-the Tax Magazine. 
rather than constrained..$^{89}$

Specialization and quality assurance. The production of legal services by means of a firm may also encourage efficient specialization by providing an important method of quality assurance. ${ }^{90}$ Information about a firm's general reputation may be a substitute for more costly information about the quality of particular specialties within the firm. In other words, information about the general reputation of a full-service law firm-one that provides a range of specialties-serves as a signal as to the quality of all its specialties. In effect, the firm pledges its entire reputation behind the quality of the services rendered by each of its specialized departments. The resulting reduction in search costs is akin to that associated with a department store. A department store's general reputation for quality shelters all of the products that it sells

89. Recognition of this potential may account for the recent development of seminars for existing and potential clients put on by a single law firm. These seminars are designed to provide direct information concerning quality to potential clients, but unlike writing and lecturing by individual lawyers, this approach features a number of the firm's lawyers as opposed to a single star. Because the emphasis of these seminars is on providing quality information about the firm's services rather than about the talents of a particular lawyer, these seminars are less likely to encourage the enhancement of only individual reputation and thus are less likely to encourage "leaving."

90. Strictly speaking, the gains from diversification of investments in human capital, and the increased incentive to invest in specialization that follows, do not result from the existence of firm-specific capital. To be sure, firms that facilitate diversification through sharing should achieve a more efficient level of specialization and, all other things being equal, should be more profitable than firms that do not. But, at least as yet, there is nothing to suggest that lawyers leaving the firm cannot easily adopt a sharing model in a new firm. This means that the increased value resulting from diversification is firm capital, like economies of scale, but not firm-specific capital. The confusion results from the fact that the existence of firm-specific capital is necessary to constrain grabbing and leaving. It thus is vital to the maintenance of the sharing model which allows the capture of gains from diversification, although these gains are not themselves firm-specific. Because both diversification and firm-specific capital are independently desirable, the result may be that success feeds on itself: Only successful firms, which already have the benefit of firm-specific capital, may be able to maintain a stable sharing model and thereby achieve the further gains from diversification.

A practice of Washington, D.C. law firms provides the best example of the value of diversification to firms hoping to achieve an efficient level of specialization. These firms perceive a competitive need to encourage the development of "serial specialists"-lawyers who become experts in various new regulatory areas, like wage and price controls, despite the knowledge that their investment in such specialties will become obsolete quite quickly. In the absence of a commitment to sharing following the demise of a particular specialty, it would be quite difficult to persuade individual lawyers to make the necessary human capital investment. This may help explain the fact that leading Washington firms like Covington \& Burling and Wilmer, Cutler \& Pickering have retained sharing models. See notes 50-51 supra. 
in numerous different departments. ${ }^{91}$ Like a department store, if a full-service firm renders lower than the promised quality of service to a client in any one specialty, the client's continued relationship to the firm with respect to all specialties is jeopardized. In essence, the full-service firm signals its quality by subjecting itself to the potential of a significant penalty-the loss of both the type of work that it might do badly and all other work as well. This method of quality assurance is simply not available to a single-specialty firm. ${ }^{92}$

The overall result should be that the output of a full-service firm may be subject to less variation in quality, and may therefore be more valuable than the output of a single-specialty firm. A higher return to the full-service firm, in turn, should lead to a more efficient level of investment in specialization and, hence, higher profits. And because the reduction in search costs that fuels the process is associated with the firm, the benefit is a firmspecific asset that further constrains ex post opportunism. ${ }^{93}$

91. The department store's evaluation of what products to carry can to some extent substitute for the purchasers' investigation of competing products. The efficiency gain results from both the greater competence of a professional-the department store buyer-at making quality comparisons and the reduction in information costs-the total investment in comparison shopping - that results from purchasers relying on a single effort by the department store rather than on individual attempts to replicate the same effort.

The department store also reduces the physical costs of searching simply by putting a variety of goods for sale at a single location and by thereby eliminating the need for a consumer to spend time going from store to store to make a number of purchases.

For a suggestion that variations in retailing may be explained in agency terms, see Jensen, supra note 15 , at 327.

92. The idea that the provision of a variety of services to a client increases the bond of quality with respect to any single service is developed in Gilson, Seeking Competitive Bids Versus Pure Passivity in Tender Offer Defense, 35 Stan. L. Rev. 51, 57-59 (1982).

93. The department store analogy suggests that changes in the competitive environment may reduce the informational value of full service law firms and, as a result, reduce the value of associated firm-specific capital. The development of the shopping center has provided an alternative to the department store both with respect to quality assurance and savings in physical search. The value of a shopping center depends on its reputation as a place where quality goods are sold. The owner of the shopping center, by placing the value of his asset at risk if the quality of goods sold at the center is low, in effect bonds the quality of the stores to whom he decides to rent space. Physical search costs are reduced by the grouping of stores in a single location with convenient parking. The result of this alternative means of reducing search costs has been to fuel the growth of specialty retailers at the expense of department stores.

The corresponding change in the competitive environment for legal services may be the increase in the sophistication of purchasers because of an increased role for corporate general counsel. Because search costs are lower for such professional purchasing agents, direct investigation of the quality of particular specialties within the firm can 
The law firm as a reputational intermediary. A final way in which firm reputation acts as a firm-specific asset occurs when it serves as a guarantee of the trustworthiness of the client. This function of firm reputation can be seen most clearly in the context of the auditor-client relationship. ${ }^{94}$ The story concerning the auditor begins with a client who wishes to sell something, the value of which depends on the client's financial condition. Examples of such things are the client's own securities or products, like computers, that requires the client to remain in business in order to support them. Although the client has an incentive (even without an audited statement) to disclose the relevant information concerning its financial condition lest the prospective customer assume that nondisclosure implies the worst, ${ }^{95}$ the prospective customer nonetheless recognizes that the client also has an incentive to provide information more favorable to itself than might otherwise be warranted. The function of the auditor, and the reason that the client pays its fee, is to place its reputation behind the accuracy of the client's financial disclosure. Without an audit, a customer must either conduct its own investigation or accept the risk posed by uncertainty concerning the client's financial condition. An audit results in efficiency gains for two reasons. First, a professional auditor can verify the accuracy of the financial statements more cheaply than can a prospective customer. Second, all prospective customers can rely on the auditor's single investigation rather than conducting their own individual investigations.

Law firms frequently play a similar role as reputational intermediaries. The first question of lawyers (and clients) who do not know much about the party on the other side of a transaction commonly concerns the identity of the other party's lawyer. The willingness of a respected firm to represent the unfamiliar principal provides favorable information about the quality of the party. Similarly, most practitioners at one time or another have accepted a statement of fact by an opposing party because that

replace reliance on indirect signaling. See note 120 infra and accompanying text. This would not, however, entirely eliminate the possible cost advantages flowing from effective diversification that a full-service firm might enjoy. See note 90 supra.

94. See, e.g., DeAngelo, supra note 75; Wilson, Auditing: Perspectives from Multi-Person Decision Theory, 58 Accr. REv. 305 (1983). For the development of the value of firm reputation in the context of investment banking, see Gilson \& Kraakman, The Mechanisms of Market Efficiency, 70 VA. L. Rev. 549 (1984).

95. See, e.g., Gilson \& Kraakman, supra note 94; Grossman, supra note 80. 
party's lawyer, whose firm has a reputation for trustworthiness, stood behind that statement. In these cases, the firm's reputation is of critical importance to the other side. It follows that the ability of the law firm in effect to rent its reputation to a client who is less well known is of substantial value to the client. Such a firm should command higher fees than one that is as technically competent, but not as well known. ${ }^{96}$

This ability of a law firm to earn returns by "renting" its reputation is a firm-specific asset. A firm's reputation for trustworthiness is unavailable to a lawyer who has left the firm. ${ }^{97}$ And recreating a reputation outside the firm may be quite expensive, in part because a larger firm is better able to act as a reputational intermediary on behalf of its client. At the core of the firm's ability to pledge its reputation on behalf of its client is a perception by other parties that the firm is "independent"- that the firm would not put its reputation on the line were the client's statements not true. But if the client represents a large percentage of firm revenue, as may more often be the case with a smaller firm, the firm's independence is called into question: Interested parties may fear that the firm might stand behind the accuracy of incorrect client statements in order to keep the client. ${ }^{98}$ Because it is difficult for a new firm to attract the number of clients necessary to facilitate renting one's reputation before that reputation exists, an already established reputation is firm-specific capital that will constrain "leaving."

96. The reputation of a law firm may also be useful in facilitating signalling by a client. For example, a client who wishes to signal to the arbitrage community its intent to defend itself against a hostile tender offer may do so by hiring a firm widely known for vigorous defensive efforts-such as Wachtell, Lipton or Skadden, Arps. From the client's perspective, what is important, at least at this stage, is not how skilled the law firm really is, but how skilled it is reputed to be.

97. Some patinae may survive leaving, however - .g., "She used to be a partner at Cravath."

98. "As a general proposition [firms] with a greater number of . . . clients have reduced incentives to 'cheat' in order to retain any one client, ceteris paribus." DeAngelo, supra note 75, at 191 (referring to audit firms). DeAngelo points out that audit fees from Equity Funding, a client involved in a massive policy fabrication fraud, represented more than $40 \%$ of total revenue of the audit firm that failed to discover the fraud. In comparison, the largest audit fee of Peat, Marwick, Mitchell, a major national accounting firm, represents only $1 / 2 \%$ of firm revenues. Id. at 192-93. Similarly, Deborah Rhode points out that the law firm which did not discover its client's fraud in the recent OPM computer leasing scandal earned some $60-70 \%$ of its total revenues from its fraudulent client. Rhode, Ethical Perspectives on Legal Practice, 37 STAN. L. REv. 589, 628 n.130 (1985). 


\section{The Relative Efficiencies of Sharing and Marginal Product Models in Developing and Sustaining Firm-Specific Capital}

Firm capital, the amount by which the value of the firm exceeds the aggregate value of its individual lawyers' human capital, is obviously a good thing: More is better than less. This should be obvious. What is not so obvious, however, is that a sharing model is better at developing and sustaining firm-specific capital than is a marginal product approach. And if this is in fact the case, it helps explain one of the puzzles we originally set out to unravel: why sharing firms not only survive, but are among the profession's most successful. Our discussion of comparative efficiency tracks the two categories of firm-specific capital that we emphasized earlier in this part-clients as sources of firm-specific capital and the firm as a means of quality assurance.

\section{Clients as sources of firm-specific capital.}

We have already examined the enormous value to a firm of established client relationships. More predictable demand allows the firm to staff more efficiently, while the investment by the client in establishing the relationship moves the firm from a competitive environment with respect to the client to one approaching bilateral monopoly. Developing and maintaining the client relationships that provide these benefits, however, requires a team effort. Most important, in order to achieve the necessary stability, the client must come to view its ties as being to the firm rather than to a particular lawyer. ${ }^{99}$ The incentives created by a marginal product approach conflict with that goal.

An important problem is the impossibility of devising a productivity formula that gives the lawyer an incentive to attract cli-

99. From the law firm's perspective, it is quite important that a client be willing to deal with a number of lawyers. Because no single client is likely to require all of a lawyer's time, each lawyer will deal with a number of clients whose demands on his time may occasionally conflict. The ability to substitute lawyers freely when such conflicts occur is critical to efficient utilization of lawyers' time, the firm's principal input. More generally, the ability to substitute lawyers facilitates the most effective use of the firm's investment in specialization.

Of equal importance, lawyers leave the firm not only by choice, but also because of death or retirement. If the client sees its relationship as being only to a particular lawyer, either of those events will eliminate the client-specific investment that ties the client to the firm and return the competitive environment to one of large numbers. Thus, the firm's best interests are served by having the client "belong" to the firm, rather than to an individual lawyer, regardless of the method of dividing the pie and, indeed, even if the ex ante sharing bargain is legally enforceable. 
ents in the first place, share them with colleagues as efficiency dictates, and even pass them on to a different partner entirely if the needs of the client or firm change. Even if a "perfect" formula could be developed for a single period, that formula itself is potentially subject to renegotiation. Productivity formulas institutionalize "grabbing." A particular formula will inevitably reflect the relative strength at the time that the formula was adopted of each lawyer's threat to leave. Because the ability to leave with the firm's clients is critical to the strength of a lawyer's threat, and because the formula is always subject to renegotiation, lawyers have an important incentive to make sure that clients in fact remain theirs, and not the firm's, regardless of the productivity formula currently in use. The marginal product approach thus creates an incentive to hoard clients which is fundamentally inconsistent with the most effective development of the client relationship as a firm-specific asset. In contrast, the sharing model has the advantage of eliminating the conflict between maximizing the value of the firm's practice and maximizing the value of an individual partner's practice that lies at the heart of the marginal product approach's problems. In a sharing model, lawyers gain the most by maximizing firm value, behavior which is more effective at creating firm capital.

\section{The firm as a means of quality assurance.}

Although a firm gains as a result of its lawyers developing their individual reputations, our analysis of a firm's ability to signal the quality of its services revealed the importance of firm, as opposed to individual, reputation. Where there are gains from minimizing the search costs of potential clients, firm reputation may often be a more accessible signal than individual reputation. Moreover, because of the potential for scale economies, an investment in firm reputation may result in more revenue than an equivalent investment in individual reputation. The task is to maximize firm profits by identifying the proper mix of investment in firm reputation and in the reputations of individual partners. A marginal product environment creates an incentive for individual lawyers to overinvest in their own reputations at the expense of the firm's reputation.

This relationship between the method of pie-division and the development of reputation as a firm-specific asset is most obvious in connection with the firm's ability to act as reputational inter- 
mediary on behalf of its clients. We have already noted the importance of size in this regard: The larger the client relative to the firm, the less credible the firm's "guarantee." Where a lawyer's income depends on the amount of work that he does for his clients, as it would under typical productivity formulas, the independence calculation shifts from the firm level to the level of the individual lawyer. Even if a client is small in relationship to the firm, it may nonetheless be quite large with respect to the individual partner who must decide whether to sign a misleading opinion letter. ${ }^{100}$ The result, of course, may be to put individual lawyers in situations where they stand to gain from actions that in fact depreciate firm-specific capital. A sharing model, because its only focus is on maximizing firm value, avoids this problem.

\section{The Missing Constraint on Shirking: Simple Formulas and the Enigma of Firm Culture}

In the last part we reached the surprising conclusion that a sharing model, which unlike the marginal product approach is able to capture the gains from diversification, may also be more efficient. The marginal product approach's efficiency failings result from agency problems-the inability to design a productivity formula that does not induce individual lawyers to pursue their own, as opposed to the firm's, best interests. Our analysis of the sharing model, however, has to this point simply assumed away the comparable agency problem associated with the sharing model-shirking. We have thus far assumed that, somehow, a sharing model would not result in a partner's putting forth less

100. See DeAngelo, supra note 75, at 191-92. This analysis has important implications for the design of regulatory regimes that seek to use an agent as an object of enforcement in order better to control the behavior of the principal. Indirect regulatory approaches of this sort are, in fact, quite common. For example, the Securities Act of 1933 imposes substantial liability on underwriters not because of any commensurate wrongdoing on their part, but because Congress saw this as a more effective way to control the issuer's behavior than the imposition of additional liability on the issuer. See Gilson \& Kraakman, supra note 94, at 605 n.164. Similarly, the Securities and Exchange Commission is currently seeking to impose an obligation on outside counsel to advise the Commission when a client refuses to make disclosure that the attorney believes to be required. A client's nondisclosure is already unlawful, but a lawyer has no obligation under the securities law to report such nondisclosures. The Commission's current efforts are premised on the hope that such a requirement will further constrain nondisclosure by the client. This approach to regulatory enforcement is examined in Kraakman, Corporate Liability Strategies and the Costs of Legal Contrals, 93 YALE L.J. 857 (1984). For our purposes it is sufficient to stress that the existence of agency problems within the firm can easily serve to deflect the direction of the regulatory effort. 
than the agreed upon effort, notwithstanding the fact that his income would be only indirectly related to his effort. This is obviously a quite heroic assumption that it is now time both to acknowledge and to relax. In fact, the shirking problem is Januslike-either easy to monitor and straightforward to remedy, or difficult to discover and even more difficult to solve-depending upon how you look at it.

Consider first its easy face. The problem is to devise a system that identifies and penalizes those partners who are not working hard enough. The constraints on the solution are that it not interfere with the goal of risk diversification that is at the heart of a sharing model and that it not create incentives to behave strategically similar to those that plague the marginal product approach.

The great majority of law firms use detailed time records buttressed by close personal observation to identify malingerers. ${ }^{101}$ Armed with this information, firms can easily penalize those partners who work less than their colleagues. This solution, however, violates both of the specified constraints.

Because the number of hours that a lawyer works is significantly affected by the amount of work that he has to do, a system that looks primarily at hours worked directly conflicts with the goal of diversification. The very point of a sharing model is to protect individual lawyers against variations in the amount of work they have as a result of the impact both of external events upon demand for particular specialties, and of personal characteristics. ${ }^{102}$ A solution that does not distinguish between a lawyer who works fewer hours because he is shirking and one who works fewer hours because of one of the events the risk of which was to be diversified, destroys the gains from diversification.

The simple hours-worked method of restraining shirking also violates the constraint against creating perverse incentives. The effect of penalizing attorneys for not billing enough is to pit lawyers against one another in a contest to avoid having low hours

101. The pervasiveness of time-keeping in law firms is chronicled in McChesney, supra note 39 (empirical information on Virginia Bar). In any event, a time-keeping system would be necessary for billing purposes so long as the manner of computing fees put some reliance on the amount of time expended on behalf of the client in determining an appropriate charge. The fact that corporate law firms overwhelmingly determine the charge for their services based largely on an hourly rate multiplied by the number of hours expended is itself a puzzle which we are trying to understand in our current research.

102. See notes 52-53 supra and accompanying text. 
compared to their peers. The hours-billed method thus creates incentives that interfere with the sharing of work and clients that is necessary to the efficient performance of legal services as well as the creation of firm-specific capital.

Neither of these problems, however, is impossible to control. Interference with the goal of achieving diversification can be largely eliminated by creating subgroups that match the specialties whose risks are to be diversified. So long as the firm compares the number of hours that an attorney works only with those worked by other lawyers whose specialties are subject to the same risk, it does not impinge upon the diversification goal, at least with respect to investment in specialized human capital. A problem remains with respect to diversification against the risk of personal misfortune, but distinguishing between, for example, shirking and a temporary personal crisis, such as divorce, that has reduced productivity, is something that a firm should be able to accomplish. Recall that insurance markets failed to arise to address these risks because of the twin problems of adverse selection and moral hazard, both of which result from the difficulty of observing the actual characteristics of a victim or potential victim. The team character of legal practice in a commercial firm makes it much easier to distinguish real victims from impostors. While some errors will still be made, it simply is not very difficult to tell when a colleague is faking.

Firms using the hours-worked method of detecting shirking can also limit the perverse incentives this method creates. Some of the problem disappears by simply setting a minimum number of hours that members of the relevant subgroup must work. The result is to reduce a lawyer's incentive to take strategic considerations into account in deciding whether to forward work to another lawyer. As long as the forwarding lawyer has satisfied the minimum, he does not suffer as a result of passing on the work. Lawyers in danger of falling below the minimum may still have some incentive to hoard work, but this distortion may not be so bad. If there is a risk that a lawyer will fall below the minimum, it may well be more desirable for the lawyer actually to do the work himself, even though it would be less efficient for the firm. To be sure, it is possible that the minimum will become the de facto maximum, but even then the shirking threshold will have been raised.

Describing workable approaches to the easy face of the shirking problem serves to highlight the much more difficult face that 
remains. Shirking involves more than simply putting in too few hours. In this respect, the shortcoming of a time-keeping system is the same as that which we identified with any productivity formula: It is merely an imperfect proxy for what is really sought to be measured-effectiveness of legal work. In both instances, the behavioral incentives are to satisfy the formula, not to maximize firm profits. And satisfying an hour minimum still leaves substantial opportunity to shirk. There is an enormous difference between the performance of a lawyer who is simply putting in his time and that of a lawyer who is truly motivated to produce. However difficult to describe, and however impossible to monitor, we all know when our performance reflects that fine edge of motivation-the sense reflected in the colloquial description of a lawyer as "driven." And our intuition suggests that it is precisely this edge that distinguishes the most successful firms. It is hardly surprising, then, that today's conventional wisdom so strongly endorses a productivity model. Because it is impossible to devise a monitoring system that effectively distinguishes among lawyers based on their motivational levels, it is thought that a sharing model cannot be successful.

How to cure the more difficult aspect of the shirking problem and why some firms that retain the sharing model have enjoyed such outstanding success thus remain puzzles. And it is important to emphasize at the outset that we should not expect to find the explanation in some form of innovative monitoring technique. The fact is that the real attribute that requires monitoring is simply unobservable in any consistent way. As a result, our focus thus far on the traditional economic approach of observing performance and imposing a penalty when performance falls short of expectations is too narrow to catch sight of the explanation we believe is really at work here.

When the problem is stated this way, it is no longer surprising that we have to go beyond traditional techniques to find an effective constraint on the unobservable behavior of lawyers. Consider how we go about teaching children proper behavior. In raising a child, even an economist does not rely solely on instilling in the child the ability to engage in a sophisticated deterrence calculus. Too much of precisely the conduct that we want the child to forgo occurs when we are unable to observe that conduct or its consequences, or when the consequences, even if observable, are themselves too serious to serve as a lesson. Rather, 
we try to teach the child a sense of right and wrong so that the child has the benefit of an internal monitor-a conscience-to which the child's behavior is always observable. Indeed, when the child's conscience is reinforced by a desire to be perceived as "good," costless monitoring combines with a powerful positive incentive to form a quite effective method of behavior control.

The development of an internal monitor reinforced by a positive personal desire to have the desirable characteristic thus appears to be an effective means of controlling unobservable conduct. ${ }^{103}$ The success of some firms in overcoming the potential for shirking seems to us to lie in what we will call "firm culture." Through some combination of selection and socialization firms can create a powerful internalized work ethic. ${ }^{104}$ Put differently, in a firm that successfully operates a sharing model, we would expect to find. Jiminy Cricket in a three-piece suit perched on each lawyer's shoulder.

103. This response to the agency problem of shirking has been stressed before. Amartya Sen has commented that "[i]t is central to the problem of work motivation, the importance of which for production performance can hardly be ignored." Sen goes on to describe the general problem that we have identified and to focus on the critical operative solution:

It is certainly costly and may be impossible to devise a system of supervision with rewards and punishment such that everyone has the incentive to exert himself. Every economic system has, therefore, tended to rely on the existence of attitudes toward work which supersedes the calculation of net gain from each unit of exertion. Social conditioning plays an extremely important part here.

Sen, Rational Fools: A Critique of the Behavioral Foundations of Economic Theory, 6 PHIL. \& PUB. AFF. 317, 333 (1977).

Similarly, Kai Erikson explains an important function of the criminal law in Puritan Massachusetts as a way of telling people how to be part of the community, how they might achieve a desired goal, rather than as a means of creating sanctions so as to alter an individual's decision by the threat of punishment. K. Erikson, Wayward Puritans: A Study in the Sociology of Deviance (1966).

Taken to its extreme, complete internalization of the appropriate norms could eliminate the conflict of interest that gives rise to the agency problem in the first place. This result would be consistent either with the idea of completely nonconflictual production arrangements associated with Marxist thought, see McPherson, Efficiency and Liberty in the Productive Enterprise: Recent Work in the Economics of Work Organization, 12 PHIL. \& PuB. AfF. 354 (1983), or with an oppressive Orwellian system that coercively internalized work norms by brainwashing, see G. ORwell, 1984 (1949).

104. For a thoughtful discussion of the notion of "firm culture" and its importance to a firm's success, see Brill, Toward a New Excellence: Strategies and Values for Tomorrow's Successful Firms, Am. LAw., Nov. 1983, at 31. Brill's essay parallels T. PETERS \& R. WATERMAN, IN SEARCH of ExCELlENCE (1982), which attempts to identify the qualities that America's best-run companies are thought to share. Our effort here is to develop the concept of and need for firm culture within the framework of modern work on the theory of the firm. 
We recognize, of course, that an answer to the shirking problem that depends even in part on the nondollar benefits of being a respected partner, and the nondollar costs of failing to satisfy the expectations of one's peers, runs a serious risk. Our colleague Mark Kelman has noted that "[o]nce the neo-classicists begin to introduce 'psychic costs' to preserve their tautology, the choice model breaks down altogether." 105 But this need not be the case. From our perspective, one benefit of neoclassical analysis is its ability to identify with some precision the circumstances in which its frame of reference-rational maximization of tangible rewards-is unable to explain observed behavior. To be sure, a tautology results if the costs and benefits posited are simply those necessary to confirm what otherwise would have been the prediction of neoclassical theory. If, however, the failure of neoclassical theory to explain observed behavior instead triggers a serious inquiry into the character of potentially relevant noneconomic costs or benefits using the tools of whatever other disciplines seem helpful, then neoclassical analysis serves an especially useful function: It may be one of the few disciplines that effectively identifies both the questions that it cannot answer and the direction further inquiry should take.

Our inquiry, then, is into the process by which lawyers are socialized: What social mechanisms serve to instill the nonshirking values that their internal monitor helps to enforce? And while related questions have commanded substantial attention from sociologists and lawyers employing sociological analysis, ${ }^{106}$ we think our emphasis on agency and portfolio theory allows us to identify some different areas of inquiry and pose some testable hypotheses that may warrant further attention.

As an initial matter, it is obvious that the socialization of lawyers does not begin when the lawyer starts work with a firm. The concept of being a "professional"-that there is a positive personal, as opposed to economic, value to meeting the standards of one's craft-begins at least in law school. Consider, for example,

105. Kelman, Choice and Utility, 1979 WIs. L. REv. 769, 784.

106. See, e.g., J. Heinz \& E. Laumann, Chicago Lawyers: The Social Structure of the Bar (1982); E. Smigel, The Wall Street Lawyer: Professional Organization Man? (1964); The Sociology of the Professions: Lawyers, Doctors and Others (R. Dingwall \& P. Lewis eds. 1983); Abel, Toward a Political Economy of Lawyers, 1981 Wis. L. REv. 1117; Nelson, The Changing Structure of Opportunity: Recruitment and Careers in Large Law Firms, 1983 Am. B. Found. Research J. 109 [hereinafter cited as Nelson, The Changing Siructure of Opportunity]; Nelson, Practice and Privilege, supra note 3. 
the implicit message that the elite law schools transmit. Traditionally, the highest embodiment of student achievement is the law review note, an article on a legal subject, published in a professional journal and characterized by exhaustive research by the author. The piece often includes hundreds of footnotes, each of which typically contains citations of multiple authorities that support the proposition asserted in the text. Moreover, before the note is published and despite the exhaustive research undertaken by the author, the elite law reviews read literally every authority cited in order to ensure "complete" accuracy, regardless of the importance of any particular point or the likelihood that an inaccuracy would be noticed. No one who has participated in a law review cite check would contend that the cite check is motivated by any form of tangible cost-benefit analysis.

The point is reinforced by a familiar refrain on the part of law firm recruiters when they claim that their firm does only high quality work: Once the firm undertakes a task, it expends the time necessary to produce a "professional" product even if it cannot bill the client for it. This lesson-that professional quality is determined without regard to economic reward-seems to us an important part of the antishirking culture necessary to perpetuate a sharing model. It suggests, in turn, that sharing firms would more highly value graduates of elite law schools and, in particular, law review editors at those schools, than would firms that follow a productivity approach. ${ }^{107}$

107. This proposition might be empirically explored by comparing the educational background of the partners and associates in sharing firms as compared to marginal product firms. Speaking of his former colleagues at Cravath, Swaine \& Moore, one exassociate stated:

There's no one who goes there who hasn't been a superachiever all his life - the guy out of the womb in record time, the first man to have pubic hair, the four-letter man in tennis and track, the editor of his law review, Fulbright scholar and valedictorian. He lands at Cravath, Swaine \& Moore and says, "I've found my home."

Margolick, Wall Street's True Blue Chip, NaT'z L.J., Jan. 14, 1980, at 1, col. 1, at 11, col. 3.

Interestingly, one very recent examination by a sociologist of the educational background of lawyers in different large law firms did not even consider identifying the manner in which the firms investigated divided their profits. See Nelson, The Changing Structure of Opportunity, supra note 106.

There are, of course, other reasons for hiring law students with strong academic credentials. These attributes may also serve as a signal of quality since there is generally less variation in skills among students who have them. But while this suggests that such students should be attractive to marginal product firms, sharing firms should still value the reduced variability more highly. So long as every lawyer has the minimum skills necessary for practice, a marginal product firm can better tolerate variations in perform- 
The socialization of antishirking norms may well begin long before the potential attorney enters law school. The elite law schools select only high achievers, many of whom have already demonstrated a willingness to work more than the amount simply required to achieve high grades. And it may be that particular social or ethnic environments are more effective at instilling these values than are others. ${ }^{108}$ If certain background attributes are signals of antishirking values, we would expect sharing firms to place greater emphasis on these characteristics, especially if the firm is unable to hire law school graduates with the highest credentials. ${ }^{109}$ A sharing firm's commitment to other values typically associated with emphasis on academic achievement-a commitment to meritocracy-would complicate an empirical test of this hypothesis. It would thus be interesting to know whether sharing firms that successfully recruit law school graduates with outstanding credentials place less emphasis on social characteristics than do sharing firms whose hiring programs are less successful. ${ }^{110}$

To this point we have emphasized that screening techniques can be means by which sharing firms reduce the risks of shirking. We would also expect sharing firms to employ training tech-

ance because its method of allocating income can take these variations into account. In sharing firms, variability in performance is more threatening because the greater the variation in the productivity of its lawyers, the greater the incentive for grabbing and leaving.

108. $C f$. T. Sowell, The Economics and Politics of Race: An International. Perspectrve (1983) (examining comparative success rates of ethnic minorities in different countries).

109. Personal background may also facilitate evaluation of personal traits. Cf. Carr \& Landa, The Economics of Symbols, Clan Names, and Religion, 12 J. Legal Stud. 135 (1983) (value of group membership as a signal); Landa, $A$ Theory of the Ethnically Homogeneous Middleman Group: An Institutional Alternative to Contract Law, 10 J. Legal Stud. 349 (1981) (informational value of shared personal traits).

110. Portfolio theory suggests a way in which limiting firm members to lawyers with similar social and/or ethnic backgrounds may be economically beneficial. Even in a firm committed to a sharing model, a lawyer cannot completely diversify his or her portfolio. The absence of a market for the lawyer's equity investment in the firm, see note 30 supra, means that the firm's investment decisions-for example, whether to open branch offices-will depend on the risk preferences of its partners, not just on whether a particular decision maximizes firm value. The separation theorem, in other words, does not apply. See E. Fama \& M. Jensen, Organizational Form and Investment Decisions 8 (Jan. 13, 1984) (University of Rochester Managerial Economics Research Center Working Paper No. MERC 84-02). In this situation there is an obvious benefit to limiting admission to partnership to those lawyers who share similar preferences. Social and ethnic background may be informative signals of such preferences. See sources cited in note 109 supra. 
niques intended to reinforce the earlier socialization of those whom their screening has identified. This may help explain the lengthy period necessary to attain partnership in firms committed to the sharing model, ${ }^{11}$ as well as the historical pattern of "up and out," pursuant to which associates who are not made partners are forced to leave the firm even though they may still be able to play an economically valuable role. ${ }^{112}$ The values of a sharing model may not allow for a second class of law firm citizen. ${ }^{113}$ From a training perspective, the length of time required to attain partner status may facilitate a mentor approach to legal training. This may in turn have the advantage of exposing a young lawyer not only to the techniques of legal practice, but to the attitudes of the mentor as well. ${ }^{14}$

In all events, our analysis is meant to be suggestive, not comprehensive. It is apparent that these law firm characteristics may

111. Once there is sufficient information to evaluate the professional skills of a lawyer, there is no longer any purely financial reason to withhold "partnership" under either a marginal product approach or a sharing model. Under the former, the lawyer will never get more than he is "worth"; under the latter, becoming a partner earlier would merely increase the number of steps to parity, leaving lifetime compensation the same. See text accompanying note 53 supra. This leaves out, however, an important element: the leverage resulting from the associates who are not made partners. A partnership in a sharing firm is worth more, ceterus paribus, than a partnership in a marginal product firm because of diversification. One way or another, an associate ought to be willing to pay more for a chance at the more valuable payoff. This greater price can be exacted in a number of ways, including a longer period before the partnership decision, a smaller proportion of otherwise qualified associates being admitted to the partnership, or higher expected hours. A longer period to partnership thus may serve a revenue maximizing as well as a socialization function.

112. See note 7 supra.

113. A productivity model, which necessarily contemplates a number of classes of citizens, should find the phenomenon less troublesome. Thus, we expect that increasing emphasis on productivity should lead to renewed interest in the idea of permanent associates. See note 7 supra. After all, if you are making less money than your peers, does it really matter what you are called? If it does matter, it would be foolish not to call them partners and simply continue to pay them less.

114. Recognition of the importance of techniques for screening and training with respect to antishirking norms has powerful implications for the question of lateral hiring of partners by a sharing firm. Not only would the absence of screening and training make lateral hiring more risky, but the very fact that the candidate was willing to leave his present firm would signal a willingness to engage in grabbing and leaving. Thus, we would expect sharing firms to engage in very little lateral hiring. We can imagine a possible exception, however, for lateral hiring of demonstrably hardworking career government attorneys who will have already shown their commitment to professionalism without regard to economic rewards. An example might be the lateral entry of Theodore A. Levine, former Associate Director of the Securities and Exchange Commission's Enforcement Division, as a partner in Wilmer, Cutler \& Pickering. See 16 SEc. REg. \& L. REP. (BNA) 118 (Jan. 20, 1984). 
serve other functions as well. ${ }^{115}$ Recognition of the importance of socialization to the success of diversification does, however, suggest fruitful avenues of future research. ${ }^{116}$

\section{The Changing Legal Environment}

Our analysis to this point suggests the potential strength of a sharing model as the basis for organizing a corporate law firm. A partnership in which lawyers share income provides the possibility for individual lawyers to diversify their human capital. Indeed, a seniority-based system of dividing the partnership pie is an outstanding way to diversify. We have seen that shirking, grabbing, and leaving pose threats to a sharing firm's stability and profitability. Nonetheless, productivity-based divisions of partnership income are not superior to a division based on sharing principles. Sharing firms can minimize shirking problems by

115. See, e.g., Leibowitz \& Tollison, Eaming and Learning in Law Firms, 7 J. LEGAL STuD. 65 (1978); Nelson, The Changing Structure of Opportunity, supra note 106.

116. Note that a firm culture of the type we have described thus far-one that equates professionalism with a lawyer's capacity to work hard at his craft without an overriding need for economic incentives- does fail in a critical way by glorifying only the worker, not the rainmaker. From this perspective, we expect that the single biggest problem in sharing firms is to get lawyers to work on bringing in clients, an activity that a firm culture that reduces shirking by emphasizing professionalism may underemphasize. This problem was raised in an article discussing the Washington, D.C. firm Covington \& Burling, where "partnership shares are generally distributed evenly among those of the same general age":

Observers point to an unmistakable shift in the caliber of key partners at the firm: a gradual transfer of the reins of power from the strong-willed, charismatic men of a generation ago to a cadre of able but colorless "technocrats" possibly without the social skills and street smarts that let their predecessors attract and keep clients.

"When you look at the senior-most people at Covington \& Burling, the people on whom the firm's reputation was built," says one former associate, "you see a different person than you see if you look at the mid-level partners. They are more colorful, more risk-oriented, maybe even more fun."

Another Covington alumnus put it this way: "I would rather spend a night with any partner over 55 than any under $45 . "$

Marcus, supra note 50 , at 28 , col. 1 .

Interestingly, the more sophisticated the client, the less serious this problem should become. Recall that a knowledgeable client is more likely to select a lawyer based on direct investigation of quality, a form of consumer behavior which encourages scholarly writing and seminar participation as a means of attracting clients. See text accompanying note 88 supra. These activities, of course, are entirely consistent with the firm culture we have described in the text. The shift in method of client attraction from one based on personality to one based on professionalism parallels the shift in the character of the lawyers between generations at Covington, and takes on particular significance in light of the growing sophistication of corporate purchasers of legal services. See text accompanying notes 119-120 infra. 
a variety of monitoring techniques and by developing a supportive firm culture. Moreover, the concept of "firm-specific capital" explains why some sharing firms achieve substantial efficiencies, tend to be among the most profitable law firms, and avoid the risks of grabbing and leaving. We have seen that the absence of firm-specific capital contributes to instability. In a sense, then, our analysis suggests a paradox: "Sharing" enhances the success of successful firms with substantial firm-specific capital while contributing to the instability of less successful firms without much firm-specific capital.

All of this poses an obvious question: Will there be more or less sharing in the future? Like the saber-toothed tiger, are seniority-based sharing firms magnificent creatures suited to an earlier age and likely soon to disappear? Or will some firms that succeed in the 1980s and 1990s continue to divide profits on sharing principles? Predicting the future is necessarily a hazardous task, in part because it must rest on assumptions about probable changes in the competitive environment for legal services. Nonetheless, our analysis suggests an important vantage point for assessing the effects of possible change. We have suggested that the survival of sharing depends upon the existence of "firmspecific capital." Therefore, after briefly describing some ongoing changes in the legal environment, we now extend our analysis by assessing the impact of such changes on the ability of firms to accumulate firm-specific capital. Our conclusion can be easily summarized: It will become increasingly difficult both to build and to sustain firm-specific capital in the future because of the increased sophistication of purchasers of legal services. No longer will firms be able to accumulate firm-specific capital on the basis of their clients' high information costs and naive purchasing strategies.

\section{A. The Changing Market for Legal Services-The Role of General Counsel}

The marketplace for corporate legal services is undergoing substantial change. While some of these changes relate to the structure of the firms providing services in the marketplace, the most significant changes are occurring on the demand side. Buyers are becoming much more sophisticated. General counsel for major corporations are creating a revolution and are the primary agents of change. 
A variety of anecdotal evidence supports the observation that general counsel are substantially affecting the marketplace for services provided by corporate law firms. The status of house counsel is rising in the process. The traditional perception was that only routine legal work was done in-house, and the important and interesting legal problems were necessarily referred to outside counsel. Today, however, the size of the in-house corporate legal staffs of many companies is growing very rapidly. Some corporations in fact now do nearly all their legal work inhouse.

It is not only the size of in-house legal staffs that has changed. Twenty years ago, the chief in-house lawyer for a corporation was commonly viewed as a competent professional who probably would not quite measure up to partnership quality in a major law firm. Indeed, corporations quite commonly hired as general counsels senior associates who were unlikely to become partners in their law firms. Today, however, corporations regularly persuade important partners in major law firms to resign from the partnership to become general counsel. ${ }^{117}$

General counsel and other top corporate executives are becoming much more sophisticated about the process of buying legal services. To be an effective consumer of legal services requires, of course, information about the performance of particular lawyers and law firms. Legal newspapers, conferences, seminars, and trade associations are now augmenting the informal networks by which general counsel in the past exchanged information. One important indication of the breadth of the change-the clear recognition of the importance of buying, as opposed to selling, legal services-involves the creation of the American Corporate Counsel Association. While the American Bar Association has long had a section devoted to in-house counsel, corporate counsel formed this new organization, which is quite independent of the $\mathrm{ABA}$, in part because they saw their interests as purchasers of legal services as different from those of

117. Among numerous examples of prominent private practitioners joining the ranks of general counsel are former Federal Judge and Pillsbury, Madison \& Sutro partner Charles Renfrew at Standard Oil of California, former Deputy Attorney General Schmuts at GTE, former Orrick, Herrington partner Maryellen B. Cattani at Transamerica Corporation, former Tuttle \& Taylor partner Joseph Mandel at Natomas Corporation, former Kirkland \& Ellis partner Elmer Johnson at General Motors, and former Donovan, Leisure partner Samuel Murphy at Gulf Oil. 
the law firms that provide the services. ${ }^{118}$ Moreover, since 1981 there has been, for the first time, a substantial amount of public discussion and explicit analysis by corporate executives and general counsel of the cost-effective use of outside counsel. Perhaps the best evidence that change is in the air was the nearly simultaneous organization of two seminars by quite unlikely sponsorsone by the authors, both of whom are academics, and the other by consumer advocate Ralph Nader. The explicit purpose of these seminars was to help corporations analyze how to buy legal services. ${ }^{119}$

Why are these general counsel agents for change? While they can play a number of important roles for the corporation, the most important role in terms of making the market for legal services more competitive is that of "purchasing agent." General counsel are the executives who decide what legal services are purchased and from whom. One alternative is to do some legal work "in-house"-in essence for the corporation to create its own law firm. The general counsel is also typically responsible for deciding who does the corporation's legal work when it is farmed out to law firms. It certainly appears that general counsel are becoming increasingly sophisticated about these decisions, and more knowledgeable about how to make the marketplace more effective. ${ }^{120}$

118. See Pressman, In-House Counsel Seek Louder Voice in Legal Profession, L.A. Daily J., Nov. 23, 1982, at 1, col. 6 .

119. See A Corporate Campaign to Slash Legal Costs, Bus. WK., May 25, 1981, at 90; White, Over-Buying Legal Services, S.F. Chron., May 14, 1981, at 29, col. I; Nader Offers Business Legal-Fee Tips, N.Y. Times, Apr. 13, 1981, at D1, col. 3; R. Gilson \& R. Mnookin, Reducing the Cost of Outside Counsel: Strategies for Controlling Your Company's Legal Fees (June 5, 1981).

120. The managing partners at two leading Los Angeles law firms-Warren Christopher at O'Melveny \& Myers and Daniel Frost at Gibson, Dunn \& Crutcher- believe that the increased sophistication of in-house counsel has created a new and challenging competitive environment for their law firms. According to Christopher:

You can't try to buck the tide of in-house sophistication. We should be sitting down with these clients and telling them that we understand that they have a budget and a board of directors to report to and that we know we can't just keep grinding out [billable] hours oblivious to that ... . The improvement in the quality of in-house staff below the general counsel . . . is probably the principal change I can see after being away for four years, and we must be sensitive to that.

Brill, L.A.'s Management Moguls, AM. LAw., Mar. 1982, at 6. See also Fried, The Trouble with Lawyers, N.Y. Times, Feb. 12, 1984, § 6 (Magazine), at 56. 


\section{B. The Pressure on Firm Capital}

What will be the effect of these changes in the marketplace on the organizational structure of large law firms? We suspect that to some significant extent the existence of firm-specific capitalthe glue that we believe has held seniority-based law firms together-is dependent upon high information costs and unsophisticated purchasers. As a result, we predict that the increased sophistication of general counsel in purchasing legal services will reduce the value of firm-specific capital. There are a number of reasons for this conclusion.

First, as we have shown in Part III, some clients create substantial amounts of firm-specific capital because they provide a predictable flow of work. Substantial amounts of routine legal work, especially work that can be handled largely, if not entirely, by associates, will generate a generous return to the firm-a return that helps hold the firm together. We predict that more and more corporations will continue to bring routine or repetitive legal work in-house. Even where it is not brought in-house, general counsel will realize that there is no need to hire lawyers from expensive firms to service or supervise this work. Such work will therefore no longer remain a source of extra profits in the future, and to that extent firm-specific capital will diminish.

The necessity of attaining client-specific information-intimate knowledge about a particular client and about that client's special needs-creates a second source of firm capital. As we explained above, once a law firm has made an investment in such information, that firm has a significant cost advantage over potential competitors. Here too, however, sophisticated general counsel may well be able to reduce if not eliminate the value of this competitive advantage. By internalizing those tasks that require the most client-specific information, by undertaking the coordinating role concerning different aspects of the client's work, and by simply taking a more active role in the decisionmaking process, the general counsel can reduce the need for the law firm to invest in client-specific information. As a result, general counsel can reduce their companies' dependence on one firm, and thus facilitate the concurrent use of a number of law firms. The ability to rely on several firms can, among other things, enable companies to signal their current law firms that they are ready, willing, and able to shift their work to other firms should they be faced with unfavorable shifts in quality or price. 
Should incumbent firms retain some monopoly power resulting from the advantage that they derive from their possession of client-specific information, the critical issue in a bilateral monopoly will concern the division of the "rent" between firm and client. Will the law firm be able to charge the client only slightly less than the fee that would be charged by a competitive firm? Or instead, will the law firm charge the client a fee that is more closely associated with the law firm's cost of providing services in this particular transaction? While we have no data to demonstrate the fact, and theory suggests no determinate answer, it is our hunch that general counsel are becoming more effective negotiators in this bilateral bargaining game.

We also emphasized in Part III how a law firm's reputation is a source of firm-specific capital because clients often have difficulty evaluating the quality of legal services. Here again, sophisticated general counsel, for whom the costs of direct investigation of quality are relatively lower, are less likely than corporate executives to pay a premium because of a firm's general reputation. Often, they can efficiently search for and hire a particular lawyer, a process made easier by the recent increased pooling of information concerning the past performances by law firms. The catchphrase now is: "Shop for a lawyer, not a law firm." General counsel now actively attempt to choose a particular lawyer for a particular piece of work, as opposed to relying on a given law firm for general representation. ${ }^{21}$ Our analysis also suggests that to the extent that specialized, unusual, or difficult work makes up an increasing proportion of the services demanded by corporate clients when they hire outside lawyers, ${ }^{122}$ it is more likely that a reputation for quality will be associated with particular partners, rather than with the firm itself. While we lack systematic data to demonstrate the fact, the demand for specialized services (as opposed to general representation) may be more likely to come to a firm because of a particular lawyer than be-

121. For example, the first sentence of the National Association of Broadcasters' Guidelines for Retaining Outside Counsel states: "NAB retains individuals rather than firms as its outside counsel." Nelson, Krasnow Exits Thriving NAB Law Department, Legal Times, Feb. 20, 1984, at 2, col. 1, at 6, col. 3.

122. One of the methods implemented by corporate counsel is to parcel out work to a number of firms, using each only in a clearly defined specialty area for which it has demonstrated its competence. A general counsel of a major corporation has stated: "Brand loyalty to the company's old firm no longer has much weight. It's specialty expertise and service that count now."

Heintz, Elements of Law Firm Competition, supra note 46, at 15, col. 3. 
cause of the firm. The result is a reduction in firm-specific capital and the creation of further pressure on the ex ante sharing bargain.

These changes in the market for legal services will certainly not eliminate all of the sources of firm-specific capital. Inevitably, there will be some returns to scale and scope from having effective team procedures that provide for substantial firm-specific capital. Nevertheless, the analysis to this point does permit some predictions about the direction of future changes.

\section{Some Predictions About the Future of the Law Firm}

The foregoing analysis suggests that the market for legal services in the future should tend to diminish, but certainly not eliminate, firm-specific capital. What implications does this have for the stability and structure of corporate law firms?

First, we predict that boutique law firms-those that specialize in a single area-will not represent the wave of the future. A boutique can develop substantial economies of specialization and scale. But our analysis reveals an important disadvantage to the boutique: its lack of diversification. The individual lawyer in a boutique law firm faces the ever present risk that the specialty will somehow fall out of fashion. Because of this disadvantage, we think a large, more diversified firm will have important competitive advantages. While the increased sophistication of purchasers should decrease reliance on the brand name of the large "department store" firms, the "cost savings" of diversification remain. We predict a continuation of the trend by which many successful boutiques ultimately diversify themselves by offering a broader range of legal services or merging into more general firms. Absent such diversification, we predict that most boutiques will not have long-term institutional lives beyond the retirement of their founding partners. In addition, we would predict that those boutiques that do survive longer will be in areas of practice where there is a reasonably stable long-term demandtax and labor may be good examples.

Second, we do not think that seniority-based, lockstep systems of dividing partnership income will disappear entirely. Indeed, we predict that ten years from now, a number of the most successful firms will still have seniority-based systems. For reasons discussed above, such systems have important potential advantages. They provide outstanding diversification and reinforce 
a culture in which clients are viewed as firm clients and in which efficient teamwork is encouraged. In light of these advantages, and the fact that a number of firms today obviously have substantial amounts of firm-specific capital, we expect that some of these firms, notwithstanding increased competitive pressures, will be able to retain seniority-based systems and indeed profit because of such systems.

For some firms, however, the increased competitive pressures will reduce the value of their firm-specific capital to the point that the retention of the seniority-based system will become impossible. Some of these firms may turn to productivity-based methods of division that will allow some partners to "grab" a larger share of the profits. Other firms will split up, as partners leave with certain important clients. In essence, we therefore expect that in the next ten years, as in the last four or five, a number of large firms with seniority-based systems will be forced to change.

We do not believe that this trend toward productivity formulas will increase the stability of larger firms. To the contrary, we think it is the existence of firm-specific capital that yields stability and, for reasons already described, we think it more difficult to develop firm-specific capital in a firm that allocates profits by means of a marginal product approach. Moreover, because it is hard to define and to measure productivity, the potential for disagreement among partners always exists. Indeed, a firm culture that makes it important for individual lawyers to be able to identify particular clients as their own could lead to inefficiencies. Finally, where disagreements do occur, split-offs may be more likely in a firm where the culture is one which emphasizes the achievement of individual lawyers. This is not to say that there will not remain highly successful, stable firms that allocate on the basis of marginal product - the long-time profitability of Hale \& Dorr certainly suggests this is possible. Instead, our prediction is less ambitious-that the movement towards marginal product approaches will not in and of itself create greater stability.

Will many new firms join the ranks of major law firms during the next ten years? How likely is it that any newcomers will allocate the partnership pie on the basis of sharing principles? Our short answer is that we think most of the giant firms ten years from now will be the same firms that are largest today, and that it is not necessarily the case that newcomers will follow the same process of growth as did the older giants. In explaining why, sev- 
eral observations seem appropriate. First, we think it is easier to retain firm-specific capital than to create it. This means that existing major firms will have a substantial competitive advantage. They developed at a time when market conditions made it easier to accumulate firm-specific capital. Presently, the process of accumulation is much more difficult. Firms that have already accumulated substantial firm capital and that have already developed a culture based on sharing principles, however, should have a somewhat easier task defending this capital in contrast to the more difficult task of creating it anew. In this sense, a historical perspective is very important. The market conditions that a firm faces at the time that it develops can substantially influence its institutional structure. Hence, when a firm becomes large can affect how it develops. An analogy to economic development seems appropriate. A country that began the process of industrialization in the nineteenth century faced very different international competitive conditions than does a country that begins the process today. The transformation of a rural to an industrial economy in the 1980's may not be akin to the transformation of an economy that began the process a hundred years earlier. ${ }^{123}$ Thus, although we expect most of the giants in the 1980s and 1990 s to be the firms that are the giants today, we think that the new additions to the ranks will not necessarily follow the same process of growth as did the old giants.

In one important respect, however, the past may well be a prologue for the future. Several of the new firms that have experienced substantial growth over the last decade have succeeded largely because of the leadership and drive of a small number of entrepreneurial lawyers within the firm. In many of these instances, it appears that a dominant figure helped develop a firm culture based on sharing principles. Steven Brill recently noted: "The leaders-senior partners who have taken on leadership roles-of almost every successful firm that I have seen, have 'bought' their leadership role in part by sacrificing personal income for the sake of building the institution. For example, there is no way in any given year and by any standard-business-produced, fees-generated, seniority, skills-that Marty Lipton and other name partners at his firm aren't worth more than two and a half times what the most junior partner is worth, or that Lloyd

123. See, e.g., A. Gerschenkron, Economic Backwardness in Historical PerSPECTIVE (1962). 
Cutler of Washington's Wilmer, Cutler and Pickering isn't worth more than three times his most junior partner. But that's approximately what these leaders limit themselves to. Just about every firm where I found strong credible leadership, . . . . I found a pervasive feeling that the leaders were taking out less than they were really worth by any commonsense standard."

Although Brill did not make the point in these terms, it appears that these leaders in essence created the firm-specific capital that helped glue the new firm together by declining to claim as much income as they might have, had a productivity measure been employed. Indeed the behavior of these leaders provides a key to understanding the chicken or the egg paradox described earlier. We noted that firm-specific capital and a strong firm culture are necessary for a sharing model to succeed. With these two ingredients, a sharing firm can remain stable and indeed enjoy important competitive advantages. The puzzle was: How can a firm develop such capital and culture if they do not already exist? Leadership of a particular sort may well provide the answer to this puzzle. We suspect that those newer firms that have developed along the lines of the sharing model were able to do so because dominant lawyers both set an example and in essence transformed what could have been their individual capital into firm-specific capital. We predict that in the future, as in the past, such leadership will be essential to the initial development of firms that seek to capture fully the potential advantages of a successful sharing model. ${ }^{125}$

\section{ConClusion}

In this article, we have shown how law firms organized on sharing principles can provide the opportunity for individual lawyers to diversify the risks associated with human capital. We have also revealed the inherent conflict between diversification through sharing and certain agency costs-shirking, grabbing, and leaving. The conflict is resolved, we have argued, by the

124. Brill, Leadership, AM. LAw., Sept. 1983, at 18.

125. Our analysis suggests a number of interesting questions about the development of today's successful giants that use a sharing system. For example, did these firms have a sharing model in their very early years when they were typically dominated by a few highly productive entrepreneurs? Or did this model develop with the next generation of partners when the firm grew, not because of the entrepreneurial efforts of the partners, but because the businesses of existing "firm" clients were successful and generated more legal work? 
presence of firm-specific capital which can constrain grabbing and leaving by making a sharing firm potentially more profitable for individual partners than alternatives outside the firm. Because of the potential convergence of diversification and productivity in successful sharing firms, we have focused on the sources of firm-specific capital, and have suggested that a sharing model may be more effective at creating and maintaining such capital. But we also have acknowledged that today's successful sharing firms may well have accumulated most of their firm-specific capital either in less competitive times or because of the leadership of a few unusually productive lawyers who preferred institutional development to a larger share of the profits. A concluding question, then, is whether gains from diversification are possible for firms that lack these advantages.

Throughout our analysis, we have chosen to contrast rather starkly a sharing model with a marginal productivity approach. ${ }^{126}$ The opportunity for a broader range of firms to capture some gains from diversification arises when we recognize an obvious but important refinement: There is no logical necessity that requires firms to rely exclusively on either a sharing or a marginal

126. Indeed, our consideration of a sharing model and a marginal product approach has been limited to a quite specific manifestation of each: a lockstep seniority system and a system relying upon a detailed productivity formula. For our purposes, however, the particular system used to implement either is not terribly important. To see this, it is important to distinguish between the principle on which the pie is to be divided, and the procedure by which the principle will be implemented. Suppose a firm decides to adopt a sharing model. While lockstep seniority is one method of sharing, another might be for a respected senior partner-quite likely the lawyer whose institutional commitment has underwritten the success of the firm's sharing model in the first place-to divide income based on the exercise of judgment, for example, taking into account need as well as seniority. Similarly, a marginal product approach can be implemented by a subjective productivity assessment by a small group of trusted lawyers within a firm, rather than by a rigid mechanical productivity formula. The decision between a sharing model and a marginal product approach turns on the trade-off between achieving diversification and providing incentives. In contrast, the choice among alternative means of implementing this decision turns on a judgment about the best way to insure that the members of the firm view the particular allocation as legitimate: how to insure that everyone feels the determination was a fair application of the principle. Implementation by formula-whether lockstep seniority or mechanical productivity equation-seeks fairness by eliminating individual judgment and, hence, the potential for that judgment to be affected by unacceptable influences such as self-interest or favoritism. Implementation by subjective division-an unstructured determination of who is productive or who requires a sharing subsidy - seeks fairness by substituting the individually tailored outcomes possible through personal assessment for the potentially arbitrary results of a rigid formula. The particular implementation method chosen is likely to depend heavily on the characteristics and personality of the particular firm. 
product approach. Both in theory and in practice, it is entirely possible for the method of profit division to reflect elements of both models. ${ }^{127}$ For example, a firm could allocate most of the partnership's profits according to a lockstep seniority system, but also allocate a part of the profits on the basis of productivity measures, such as hours worked and fees generated, in order to maintain incentives. Alternatively, a firm could allocate profits up to a given point by productivity measures, and then share equally beyond that point, thereby attempting to share only returns on firm, as opposed to individual, capital. The critical point is that to the extent that firms allocate profits according to a sharing principle, they provide partners with an opportunity to diversify their human capital.

Along these same lines, a firm without firm-specific capital might choose to rely on sharing principles to diversify some risks but not others, depending on the perceived cost in terms of incentives. Firms may achieve some forms of diversification at little cost in terms of shirking, grabbing, or leaving. For example, they can limit the sharing bargain to providing the equivalent of disaster insurance. Sharing would thus take place only when events have drastically reduced the value of a particular specialty-for example, the impact of the elimination of the Department of Energy on energy lawyers-and then only to the extent necessary to retrain a lawyer in a new specialty. Similarly, a group of lawyers may choose to share only the risks of disability-like events because members of the firm are confident that they can monitor each other, and that such "insurance" would not create significant incentive problems.

The possibility of tradeoffs between diversification and incentives suggests a final point that warrants particular emphasis. Recognition of the potential for gains from diversification may shed light on existing practices and provide a framework for future empirical and theoretical study. To our knowledge, there has been no systematic empirical study of how large law firmseither currently or historically-have allocated partnership profits. Empirical and historical research may well make it possible to assess, refine, or possibly even reject our hypotheses about sharing. It would be interesting to explore both theoretically and em-

127. This claim is neither surprising nor terribly bold. The formal models that dominate the principal-agent portion of the agency literature are explicitly concerned with the optimal trade-off between diversification and incentives. See note 31 supra. 
pirically how many lawyers, and what combinations of specialties, provide the best diversification, as well as what mechanisms best constrain shirking, grabbing, and leaving. It would be particularly interesting to discover whether the division of profits by law firms parallels that of other service organizations, such as investment banking firms, advertising agencies, and accounting firms. Why should lawyers be the only human capitalists who share?

This emphasis on the need for detailed investigations of actual institutions suggests an appropriate thought on which to conclude. Our focus here on theory and on polar models is intended to provide a structure to help illuminate study of the real world, not to substitute for it. And, lest anyone finish reading this article without recognizing that the complexity of the real world poses a continuing challenge to the claims of a neat theory, we close by noting the following interesting fact: Of the two firms widely considered to be the nation's most profitable, oneCravath, Swaine \& Moore-uses a sharing model and the otherSkadden, Arps, Slate, Meagher \& Flom-follows a marginal product approach. 